\title{
Pólen de gimnospermas e angiospermas em sedimentos quaternários de duas matas com Araucária, planalto leste do Rio Grande do Sul, Brasil ${ }^{1}$
}

\author{
Caroline Scherer ${ }^{2,3}$ e Maria Luisa Lorscheitter ${ }^{2}$
}

Recebido em 6/06/2008. Aceito em 6/10/2008

RESUMO - (Pólen de gimnospermas e angiospermas em sedimentos quaternários de duas matas com Araucária, planalto leste do Rio Grande do Sul, Brasil). Catálogos polínicos de material contido em sedimentos servem como referência em estudos de reconstituição paleoambiental dos últimos milênios. Nesse contexto, a análise palinológica de dois perfis sedimentares do interior de matas com Araucária do estado do Rio Grande do Sul foi realizada. São apresentadas descrições dos grãos de pólen e dados ecológicos dos respectivos táxons de gimnospermas e angiospermas. A análise envolveu amostras de dois perfis sedimentares do Quaternário Tardio de São Francisco de Paula (perfil 1: Alpes de São Francisco, 29 $9^{\circ} 29^{\prime} \mathrm{S}-50^{\circ} 37^{\prime} \mathrm{W}$, perfil 2: Banhado Amarelo, $29^{\circ} 18^{\prime} \mathrm{S}-50^{\circ} 08^{\prime} \mathrm{W}$ ), coletados com o Amostrador de Hiller. O processamento químico das amostras seguiu o método padrão, com $\mathrm{HCl}, \mathrm{HF}, \mathrm{KOH}$, acetólise e montagem das lâminas em gelatina-glicerinada. A análise foi realizada em microscopia óptica. A descrição de cada material é acompanhada de ilustrações. São apresentados palinomorfos de três gimnospermas e 65 angiospermas. A grande riqueza do espectro polínico mostra a potencialidade deste material em oferecer informações ambientais relevantes no estudo da gênese e dinâmica da mata com Araucária.

Palavras-chaves: palinologia, Quaternário, taxonomia

ABSTRACT - (Gymnosperm and angiosperm pollen in Quaternary sediments from two Araucaria forests on the Rio Grande do Sul State eastern plateau, Brazil). Sedimentary pollen catalogues are aids in the study of paleoenvironmental reconstruction of the last millennia. In this context, palynological analysis of two sedimentary profiles from inside Araucaria forests of Rio Grande do Sul state was done. Descriptions of gymnosperm and angiosperm pollen and ecological data of the respective taxa are presented. The analysis involved samples of two sedimentary profiles from the Late Quaternary of São Francisco de Paula (profile 1: Alpes de São Francisco, 29²9'S-50³7' W, profile 2: Banhado Amarelo, $29^{\circ} 18^{\prime} S-50^{\circ} 08^{\prime}$ W), collected with a Hiller Sampler. Chemical processing of the samples followed standard methodology, using $\mathrm{HCl}, \mathrm{HF}, \mathrm{KOH}$, acetolysis and slide mounts in glycerol-jelly. The analysis was done by light microscopy. All material is described and illustrated. Palynomorphs of three gymnosperms and 65 angiosperms are presented. Pollen assemblage richness shows the potential of this material in offering relevant environmental information, in the study of genesis and dynamics of the Araucaria forest.

Key words: palynology, Quaternary, taxonomy

\section{Introdução}

Três propriedades de pólen e esporos tornam a palinologia um instrumento importante em reconstituições paleoambientais: parede celular (exina) resistente permitindo a preservação em determinados sedimentos, morfologia polínica ligada à espécie de origem e produção em grande quantidade, possibilitando análises quantitativas. A palinologia de sedimentos é, assim, uma importante ferramenta no estudo das mudanças vegetacionais e climáticas ocorridas no passado por trabalhar diretamente com material botânico, indicador de paleoambientes. Para tanto, a prévia identificação dos palinomorfos contidos nos sedimentos é imprescindível o que torna de grande valia os catálogos palinológicos de referência, tanto da flora atual quanto do material sedimentar.

A fisionomia da paisagem do Planalto leste do Rio Grande do Sul vem há muito despertando o interesse de pesquisadores, principalmente em relação à dinâmica da mata com Araucária e à própria Araucaria angustifolia (Bertol.) Kuntze nos últimos milênios. No entanto, estudos de palinologia de sedimentos, relacionados à reconstituição de paleoambientes são ainda escassos na região (Roth \& Lorscheitter 1993; Behling et al. 2001; 2004; Leonhardt \& Lorscheitter 2007; Scherer \& Lorscheitter 2008).
Visando contribuir para a pesquisa sobre paleoambientes dos últimos milênios na região, o presente trabalho apresenta o resultado da análise palinológica qualitativa de dois perfis sedimentares quaternários do interior de mata com Araucária do município de São Francisco de Paula, Planalto leste do Rio Grande do Sul, abrangendo pólen de gimnospermas e angiospermas como material de referência. Apresenta-se a taxonomia de cada material, usando descrições morfológicas sucintas e fotomicrografias ópticas. Sempre que possível dados ecológicos da planta de origem acompanham as descrições. Pólen encontrado apenas em condições desfavoráveis de preservação, mas guardando características distintivas próprias, foi também incluído, visando oferecer material de referência mais completo. Dáse, assim, continuidade à análise do conteúdo palinológico dos dois perfis, cuja primeira parte (fungos, algas, briófitos e pteridófitos) já foi apresentada por Scherer \& Lorscheitter (2008).

\section{Material e métodos}

Os perfis localizam-se em Alpes de São Francisco - perfil 1 (2929'S$50^{\circ} 37^{\prime} \mathrm{W}$, com $132 \mathrm{~cm}$ de comprimento, base datada em $12650 \pm 70$ anos AP, Beta 200630) e Banhado Amarelo - perfil 2 (2918'S$50^{\circ} 08^{\prime} \mathrm{W}$, com $101 \mathrm{~cm}$ de comprimento, base datada em $3840 \pm 40$ anos AP, Beta 233965), (Fig. 1). Na coleta dos perfis foi usado o Amostrador de Hiller (Faegri \& Iversen 1989), com o qual foram

\footnotetext{
1 Parte da Tese de Doutorado da primeira Autora

2 Universidade Federal do Rio Grande do Sul, Instituto de Biociências, Departamento de Botânica, Porto Alegre, RS, Brasil

3 Autor para correspondência: cacabio@yahoo.com.br
} 


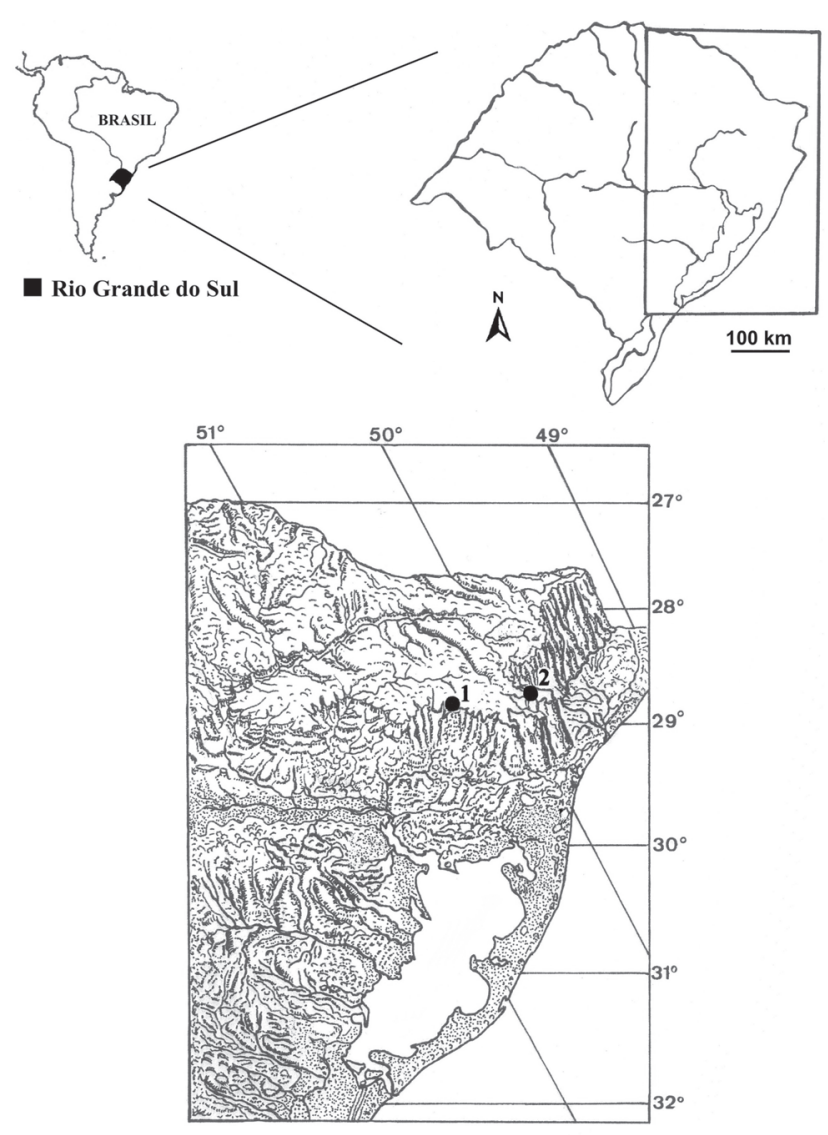

Figura 1. Estado do Rio Grande do Sul e localização dos perfis sedimentares estudados: 1. Alpes de São Francisco (29⒉'S-50³7’ W), 2. Banhado Amarelo (2918'S-5008'W), município de São Francisco de Paula, Rio Grande do Sul, Brasil.

obtidas 15 amostras do perfil 1 e oito do perfil 2, espaçadas em intervalos regulares de cerca de $10 \mathrm{~cm}$, cada uma de $8 \mathrm{~cm}^{3}$. As amostras para palinologia foram processadas pelo método padrão para material do Quaternário (Faegri \& Iversen 1989), usando-se HCl, HF, KOH e acetólise, com filtragem em malha de 250 ìm e montagem das lâminas em gelatina-glicerinada. A análise palinológica foi feita em microscópio óptico Carl Zeiss Jena. O material polínico foi fotomicrografado em microscópio óptico Diaplan Leitz, em geral no aumento de 1000 x (filme T-MAX 100).

Na identificação botânica foi utilizada a palinoteca de plantas atuais do Laboratório de Palinologia do Departamento de Botânica da Universidade Federal do Rio Grande do Sul e bibliografia especializada. Os grãos de pólen foram determinados na categoria taxonômica mais inferior possível. A denominação "Tipo" foi empregada quando não houve possibilidade de assegurar a determinação, conforme o usual em palinologia de sedimentos (Berglund 1986). Foram acrescentados números após os nomes de grãos de pólen pertencentes a uma mesma categoria taxonômica que apresentam tipos morfologicamente distintos. O material foi separado por números quando não houve possibilidade de determinação, visando futura identificação. A ordenação sistemática seguiu Bold et al. (1987) para as gimnospermas e Cronquist (1981) para as angiospermas. A terminologia utilizada baseou-se no glossário de Punt et al. (2007). Os táxons foram descritos de modo sucinto, ressaltando as características morfológicas básicas para a identificação. As medidas foram realizadas em ocular de fio móvel e convertidas para micrômetros. As descrições do material são acompanhadas de dados ecológicos da planta de origem, fornecendo informações para análise de paleoambientes. Todo o material se encontra depositado na palinoteca do Departamento de Botânica, Instituto de Biociências, Universidade Federal do Rio Grande do Sul sob as siglas ASF (Alpes de São Francisco) e BAM (Banhado Amarelo).

\section{Resultados e discussão}

A análise revelou 68 táxons distintos, preservados ao longo dos dois perfis sedimentares, correspondendo a três de gimnospermas e 65 de angiospermas. A riqueza do material encontrado mostra sua potencialidade em oferecer relevantes informações na pesquisa sobre a gênese e a dinâmica da mata com Araucária nos últimos milênios.

\section{Gimnospermas \\ Divisão Coniferophyta \\ Classe Coniferopsida \\ Ordem Coniferales \\ Família Araucariaceae}

\section{Araucaria angustifolia (Bertol.) Kuntze}

Fig. 2

Globoso, aproximadamente esférico, apolar. Robusto. Inaperturado, exina fina e delicada, resultando em um grão irregularmente dobrado. Escabrado. Dois minúsculos descolamentos de parede celular, opostos, semelhantes aos de um pólen bissacado, podem ser perceptíveis em alguns grãos. Diâmetro: 67-92 $\mu \mathrm{m}$. Dados ecológicos: pioneira e heliófita, possibilitando a expansão das florestas sobre os campos principalmente no Planalto, em altitudes acima de $500 \mathrm{~m}$ (Backes \& Irgang 2002); irradia-se como elemento isolado sobre os campos limpos, formando agrupamentos, de início bastante esparsos, que vão tornando-se cada vez mais densos, até constituir capões de pinhais, preferencialmente em depressões e junto a cursos d'água (Reitz et al. 1983). Principal elemento fisionômico da Floresta Ombrófila Mista.

\section{Família Podocarpaceae}

\section{Podocarpus lambertii Klotzsch ex Endl.}

Fig. 3

Esferoidal a elipsoidal, bilateral e heteropolar. Monoulcerado no pólo distal, escabrado. Bissacado. Sacos robustos, com finas linhas irregulares, formadas pelo descolamento da exina. Comprimento total (incluindo sacos): 52-115 $\mu \mathrm{m}$. Altura total (incluindo sacos): 35-107 $\mu \mathrm{m}$. Eixo equatorial maior: 35-101 $\mu \mathrm{m}$. Eixo equatorial menor: 32-95 $\mu \mathrm{m}$. Comprimento dos sacos: 24-68 $\mu \mathrm{m}$. Largura dos sacos: 50-94 $\mu \mathrm{m}$. Obs: a nomenclatura para as medições seguiu Erdtman (1957). Dados ecológicos: pioneira de médio porte, precursora em campos e capoeiras, indicada para recuperação de áreas degradadas ou matas ribeirinhas (Backes \& Irgang 2002), espécie esciófita e heliófita (Reitz et al. 1983). Ocorrente no Planalto, junto à mata com Araucária, mas também mais ao sul, sobre as elevações da Serra do Sudeste.

\section{Divisão Gnetophyta \\ Classe Gnetopsida \\ Ordem Ephedrales \\ Família Ephedraceae}




\section{Ephedra tweediana Fisch. \& C.A. Mey.}

Fig. 4

Peroblato, fusiforme, bilateral e apolar. Inaperturado, várias dobras paralelas ao eixo maior, convergindo nas extremidades (vista equatorial menor). Eixo polar: cerca de $25 \mu \mathrm{m}$. Eixo equatorial maior: cerca de $52 \mu \mathrm{m}$. Dados ecológicos: espécie escandente, no Brasil ocorrendo apenas no Rio Grande do Sul onde habita terrenos arenosos e secos do sul da Planície Costeira até os arredores de Porto Alegre (Baptista et al. 1979). Segundo Waechter (1990), é comum nas restingas arenosas das margens ocidental e setentrional da Laguna dos Patos, onde atinge seu limite norte de distribuição. A rara ocorrência no perfil sedimentar de Alpes de São Francisco pode ser explicada por possíveis massas de ar ascendentes, desde os terrenos baixos da Planície Costeira e zonas adjacentes.

\section{Angiospermas \\ Divisão Magnoliophyta \\ Classe Magnoliopsida \\ Subclasse Magnoliidae \\ Ordem Magnoliales \\ Família Winteraceae}

\section{Drimys brasiliensis Miers}

Fig. 5-7

Tétrade tetraédrica. Oblato, radiossimétrico e heteropolar. Circular em vista polar. Monoulcerado no pólo distal, perreticulado. Retículo grosseiro, diminuindo em direção à abertura, até desaparecer junto ao ulcus. Columelas evidentes, sustentando o muro. Diâmetro da tétrade: 48-52 $\mu \mathrm{m}$. Grão: Eixo polar: 22-27 $\mu \mathrm{m}$. Eixo equatorial: 33-37 $\mu \mathrm{m}$. Dados ecológicos: árvore de pequeno porte, acompanhando o domínio da mata com Araucária sobre o Planalto na transição campo-floresta (Schultz 1990; Backes \& Irgang 2002). Característica dos capões de campos, áreas alagadas e florestas de altitude nas regiões Sul e Sudeste do Brasil. Esciófita ou de luz difusa, menos freqüente como heliófita e levemente seletiva higrófita (Trinta \& Santos 1997; Souza \& Lorenzi 2005).

Subclasse Hamamelidae

Ordem Urticales

\section{Urticales}

Fig. 8-9

Radiossimétrico e isopolar. Pequeno, subcircular em vista polar. Triporado, psilado. Estratificação obscura. Eixo equatorial: 14-17 $\mu \mathrm{m}$. Dados ecológicos: plantas herbáceas, arbóreas ou arbustivas (Joly 2002), em geral relacionadas à ambiente de mata.

\section{Família Ulmaceae}

\section{Celtis L.}

Fig. 10-11
Radiossimétrico e isopolar, aproximadamente circular em vista polar. Triporado, psilado, poros com espessamento anelar. Columelas nem sempre evidentes. Eixo equatorial: 29-30 $\mu \mathrm{m}$. Dados ecológicos: árvores ou arbustos, em matas (Schultz 1990; Joly 2002).

\section{Trema micrantha (L.) Blume}

Fig. 12

Suboblato a oblato-esferoidal, bilateral, apolar. Pequeno, elíptico nas vistas polar e equatorial. Biporado, psilado a escabrado. Columelas nem sempre evidentes. Eixo polar: 17-20 $\mu \mathrm{m}$. Eixo equatorial maior: 19-21 $\mu \mathrm{m}$. Dados ecológicos: arbórea, importante espécie pioneira na recomposição de áreas degradadas ou mesmo em reflorestamento inicial, amplamente distribuída. Ocorre na orla das matas e nos capoeirões, onde se torna bastante freqüente, sobretudo na mata latifoliada do Alto Uruguai e da Depressão Central (Reitz et al. 1983; Schultz 1990; Backes \& Irgang 2002).

\section{Ordem Fagales \\ Família Betulaceae}

\section{Alnus Mill.}

Fig. 13-14

Oblato-esferoidal, radiossimétrico e isopolar. Poligonal em vista polar. Tetraporado a estefanoporado com cinco poros, psilado a levemente escabrado. Poros proeminentes, com espessamento anelar característico. Exina com espessamentos em forma de arco, conectando um poro a outro. Columelas evidentes. Eixo equatorial: 31-33 $\mu \mathrm{m}$. Dados ecológicos: arvoreta, pioneira particularmente em solos pantanosos, podendo cobrir grandes áreas úmidas (Marchant et al. 2002). Distribuição principalmente em áreas pantanosas das florestas de altitude dos Andes (2.550-3.100 m), também em florestas tropicais e subtropicais de galeria e locais rochosos. Não há representantes nativos do gênero no Brasil (Joly 2002; Marchant et al. 2002). Segundo Roth \& Lorscheitter (1993), a presença do pólen de Alnus em sedimentos do Planalto do Rio Grande do Sul deve-se possivelmente pelo transporte a grandes distâncias por ventos de oeste, desde a Argentina.

\section{Subclasse Caryophyllidae \\ Ordem Caryophyllales \\ Família Amaranthaceae}

\section{Tipo Iresine P. Browne}

Fig. 15-17

Esférico, radiossimétrico e apolar. Pantoporado, per-reticulado, um poro no interior de cada lúmen do retículo. Columelas evidentes, sustentando o muro. Diâmetro: 21-31 $\mu \mathrm{m}$. Dados ecológicos: ervas ou subarbustos, anuais ou perenes, com distribuição nas regiões quentes e temperadas da América e África, ocorrendo em campos secos e arenosos, clareiras ou borda de mata. Também encontrado em dunas litorâneas (Vasconcellos 1973; Schultz 1990; Joly 2002). 
Família Amaranthaceae- Família Chenopodiaceae

10. Tipo Amaranthus L. - Chenopodiaceae

Fig. 18-20

Esférico, radiossimétrico e apolar. Pantoporado, psilado. Poros numerosos e regularmente distribuídos por toda a superfície. Columelas evidentes. Diâmetro: 24-27 $\mu \mathrm{m}$. Obs: o gênero Amaranthus, de Amaranthaceae, e as Chenopodiaceae apresentam semelhança na morfologia polínica, sendo difícil a separação taxonômica entre ambos. Preferiu-se, assim, a denominação Tipo Amaranthus L.-Chenopodiaceae. Dados ecológicos: representantes de Amaranthus são ervas geralmente anuais (Souza \& Lorenzi 2005). As espécies ocorrentes no Rio Grande do Sul crescem em terrenos alterados, como ruderais (Vasconcellos 1973). A maioria das Chenopodiaceae são ervas anuais ou raramente arbustos, muitas ruderais ou halófitas (Schultz 1990; Joly 2002).

Família Caryophyllaceae

\section{Caryophyllaceae}

Fig. 21

Esférico, radiossimétrico e apolar. Pantoporado, psilado. Poros distanciados, com característico espessamento anelar. Columelas evidentes. Diâmetro: 36-46 $\mu \mathrm{m}$. Dados ecológicos: cosmopolita, em geral ervas anuais ou perenes, raramente subarbustos ou arbustos (Schultz 1990; Joly 2002). Em ambientes abertos, campos naturais e cerrados; comuns em áreas de altitude do Sul do Brasil (Schultz 1990; Souza \& Lorenzi 2005). No Rio Grande do Sul, espécies da família ocorrem em matas, barrancos, campos, encostas, regiões pedregosas, brejos, habitando desde solos úmidos até secos (Ceroni 1973).

Ordem Polygonales

Família Polygonaceae

\section{Polygonum L.}

Fig. 22-23

Esférico, radiossimétrico e apolar. Pantoporado, perreticulado. Retículo com muros altos. Poros no interior de alguns lumens, distanciados, regularmente distribuídos. Columelas evidentes, sustentando o muro. Diâmetro: 46-58 $\mu \mathrm{m}$. Dados ecológicos: ervas ou subarbustos, freqüentes em locais alagáveis, alguns comportando-se como invasores de culturas ou ruderais (Joly 2002; Souza \& Lorenzi 2005).

\section{Subclasse Dillenidae \\ Ordem Malvales \\ Família Malvaceae}

\section{Malvaceae}

Fig. 24-25

Esférico, radiossimétrico, isopolar ou apolar. Robusto. Estefanoporado ou pantoporado, equinado. Espessamento anelar em torno dos poros. Espinhos de tamanho avantajado, columelas evidentes, especialmente perceptíveis na zona abaixo dos espinhos. Diâmetro:
48-68 $\mu \mathrm{m}$. Dados ecológicos: ervas, subarbustos ou arbustos, raramente árvores de pequeno porte, cosmopolitas, com centro de dispersão nas regiões tropicais. Espécies de ambientes variados (Schultz 1990; Joly 2002).

\section{Ordem Violales \\ Família Cucurbitaceae}

\section{Cucurbitaceae}

Fig. 26-28

Esférico, radiossimétrico e apolar. Pantoporado, equinado. Poros tênues, pouco perceptíveis. Espinhos esparsos. Columelas evidentes. Diâmetro: 48-54 um. Dados ecológicos: plantas herbáceas, trepadeiras ou rastejantes, raramente subarbustos ou arbustos (Schultz 1990; Joly 2002; Souza \& Lorenzi 2005). Família cosmopolita, preferencialmente em regiões tropicais (Schultz 1990). No Rio Grande do Sul é encontrada em capoeiras, campos ou bordas e interior de matas (Porto 1974).

\section{Ordem Ebenales \\ Família Sapotaceae}

\section{Chrysophyllum L.}

Fig. 29

Prolato, radiossimétrico e isopolar. Elíptico-comprimido em vista equatorial. Tricolporado, per-reticulado. Retículo muito fino. Sexina mais espessa que a nexina nas regiões polares. Columelas evidentes. Eixo polar: 29-38 $\mu \mathrm{m}$. Eixo equatorial: 20-22 $\mu \mathrm{m}$. Dados ecológicos: árvores e arbustos lactescentes. No Rio Grande do Sul ocorrem em matas ou capões (Reitz 1968).

\section{Ordem Primulales \\ Família Myrsinaceae}

\section{Myrsine L.}

Fig. 30-32

Oblato-esferoidal, radiossimétrico e isopolar. Circular a levemente quadrangular em vista polar, aproximadamente circular em vista equatorial. Tetracolpado a tetracolporoidado, psilado. Columelas evidentes. Eixo polar: cerca de $25 \mu \mathrm{m}$. Eixo equatorial: 26-28 $\mu \mathrm{m}$. Dados ecológicos: no Rio Grande do Sul o gênero apresenta espécies arbóreas pioneiras, com vasta distribuição (Reitz et al. 1983). As espécies desenvolvem-se em qualquer tipo de solo, sendo indicadas na recuperação de áreas degradadas. Amplamente dispersas pela avifauna (Backes \& Irgang 2002), encontram-se associadas à vegetação da mata com Araucária (Marchant et al. 2002).

\author{
Subclasse Rosidae \\ Ordem Fabales \\ Família Mimosaceae
}

\section{Tipo Acacia Mill. 1}

Fig. 33-34 
Políade elipsoidal em vista frontal. Pólen suboblato a oblato-esferoidal, radiossimétrico, heteropolar, verrucado. Poros não evidenciados. Estratificação obscura. Eixo maior da políade: cerca de $40 \mu \mathrm{m}$. Eixo menor da políade: cerca de $26 \mu \mathrm{m}$. Pólen: Eixo polar: 11-13 $\mu \mathrm{m}$. Eixo equatorial: 12-15 $\mu \mathrm{m}$. Dados ecológicos: as espécies nativas são arbustos ou árvores de pequeno porte (Schultz 1990). Gênero cosmopolita, abundantemente representado em savanas e matas (Burkart 1979).

\section{Tipo Acacia Mill. 2}

Fig. 35

Políade elipsoidal em vista frontal, hialina. Pólen oblatoesferoidal a esférico, radiossimétrico, heteropolar, psilado. Poros não evidenciados. Estratificação obscura. Eixo maior da políade: cerca de $34 \mu \mathrm{m}$. Eixo menor da políade: cerca de $24 \mu \mathrm{m}$. Pólen: Eixo polar: 9-11 $\mu \mathrm{m}$. Eixo equatorial: 9-12 $\mu \mathrm{m}$. Dados ecológicos: como em Tipo Acacia 1.
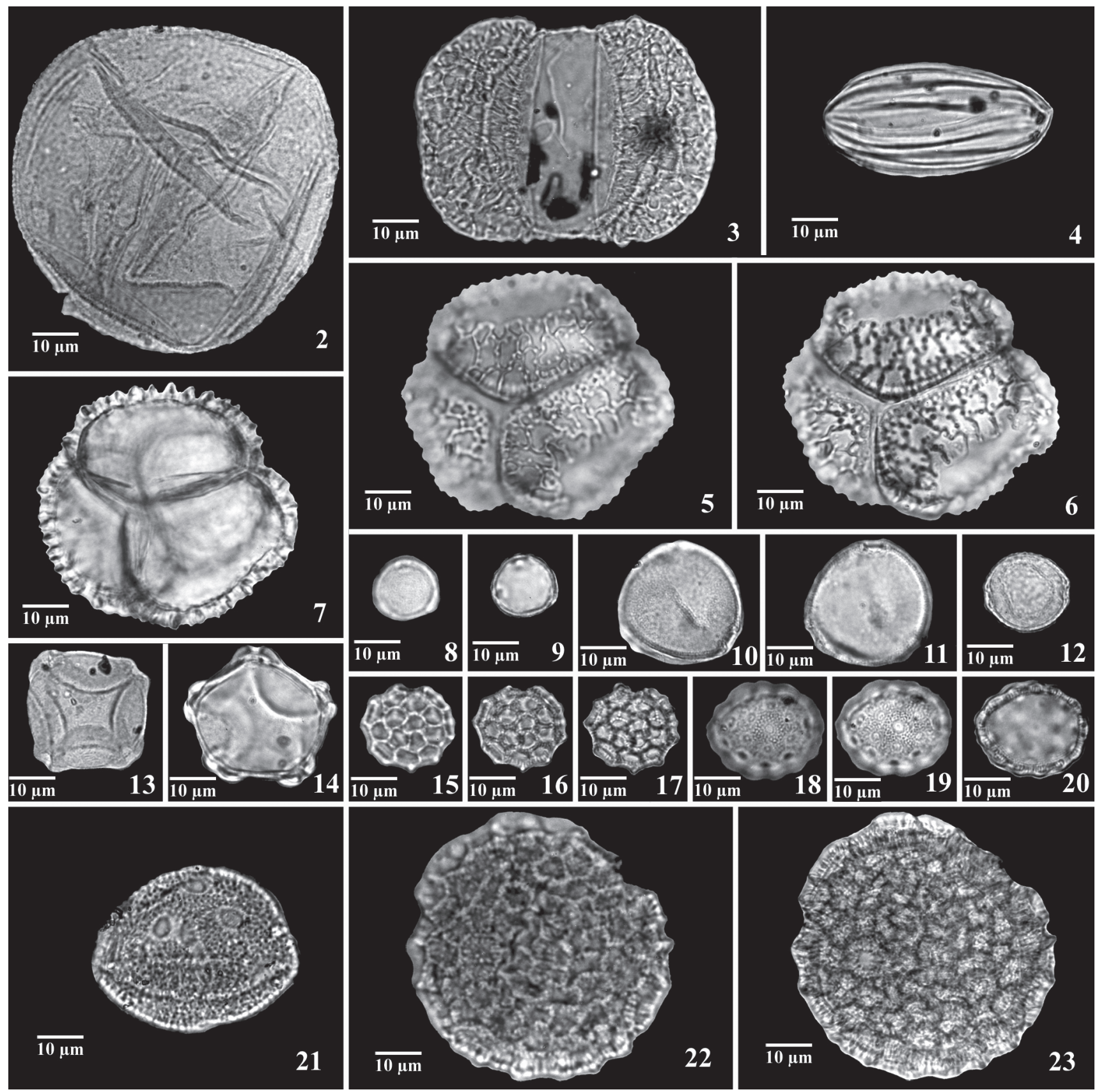

Figuras 2-23. Gimnospermas e Angiospermas. 2. Araucaria angustifolia (Bertol.) Kuntze. 3. Podocarpus lambertii Klotzsch ex Endl. (PD). 4. Ephedra tweediana Fisch. \& C.A. Mey. 5-7. Drimys brasiliensis Miers: $1^{\circ}-3^{\circ} \mathrm{pl} ; 8-9$. Urticales (P): $1^{\circ}-2^{\circ}$ pl. 10-11. Celtis L. (P): $1^{\circ}-2^{\circ}$ pl. 12 . Trema micrantha (L.) Blume; 13-14. Alnus Mill. (P); 15-17. Tipo Iresine P. Browne: $1^{\circ}-3^{\circ} \mathrm{pl} ; 18-20$. Tipo Amaranthus L. - Chenopodiaceae: $1^{\circ}-3^{\circ}$ pl; 21 . Caryophyllaceae; $22-23$. Polygonum L.: $1^{\circ}-2^{\circ} \mathrm{pl}$. (pl = planos, $\mathrm{PD}=$ pólo distal, $\mathrm{P}=$ vista polar $)$. 


\section{Mimosa scabrella Benth.}

Fig. 36-37

Tétrade tetraédrica, pequena e hialina. Pólen oblatoesferoidal a prolato, radiossimétrico, levemente heteropolar. Aproximadamente circular em vista polar. Poros não evidentes, psilado. Estratificação obscura. Diâmetro da tétrade: $15-17 \mu \mathrm{m}$. Pólen: Eixo polar: 7-10 $\mu \mathrm{m}$. Eixo equatorial: 4-11 $\mu \mathrm{m}$. Dados ecológicos: árvore pioneira da mata com Araucária, importante na incorporação de nitrogênio e fósforo ao solo através dos nódulos radiculares e queda das folhas (Backes \& Irgang 2002). Heliófita e pouco exigente às condições físicas dos solos, ocorrendo principalmente nas associações secundárias. Vastamente dispersa pelas matas dos pinhais e pelos capoeirões, onde encontra-se circunscrita às florestas com pinheiros situados em maiores altitudes, de 700 a 1.200 m (Burkart 1979; Reitz et al. 1983).

\section{Mimosa ser. Lepidotae Benth.}

Fig. 38-39

Tétrade tetragonal, subquadrangular em vista frontal. Pólen suboblato a oblato-esferoidal, radiossimétrico, heteropolar. Pólo distal alargado e pólo proximal nitidamente afilado. Porado, verrucado. Poros equatoriais salientes. Columelas levemente perceptíveis. Diâmetro da tétrade: 28-30 $\mu \mathrm{m}$. Pólen: Eixo polar: 13-17 $\mu \mathrm{m}$. Eixo equatorial: 17-18 $\mu \mathrm{m}$. Dados ecológicos: subarbustos até árvores, em locais úmidos a pantanosos (Burkart 1979).

\section{Mimosa L. 1}

Fig. 40-41

Tétrade tetragonal, circular ou subquadrangular em vista frontal. Pólen oblato a suboblato, radiossimétrico, heteropolar. Pólo distal alargado e pólo proximal nitidamente afilado. Pantoporado, microverrucado. Diâmetro da tétrade: 27-28 $\mu \mathrm{m}$. Pólen: Eixo polar: 10-14 $\mu \mathrm{m}$. Eixo equatorial: 15-16 $\mu \mathrm{m}$. Dados ecológicos: gênero de ervas e arbustos, raras vezes árvores, preferentemente heliófitas (Burkart 1979).

\section{Mimosa L. 2}

Fig. 42-43

Tétrade tetraédrica. Pólen oblato a esférico, radiossimétrico, heteropolar. Pólo proximal um pouco afilado. Aproximadamente subtriangular em vista polar. Pantoporado, verrucado, verrugas tênues. Poros em pouco número, distanciados e irregularmente distribuídos. Columelas pouco evidentes. Diâmetro da tétrade: 17-26 $\mu \mathrm{m}$. Pólen: Eixo polar: 8-13 $\mu \mathrm{m}$. Eixo equatorial: 8-20 $\mu \mathrm{m}$. Dados ecológicos: como em Mimosa 1.

\section{Família Caesalpiniaceae}

23. Bauhinia forficata subsp. pruinosa (Vogel) Fortunato \& Wunderlin

Fig. 44
Suboblato a oblato-esferoidal, radiossimétrico, isopolar. Robusto. Elíptico em vista equatorial. Tricolporado, gemado. Gemas muito grosseiras e distanciadas, irregularmente distribuídas. Columelas evidentes. Eixo polar: 45-66 $\mu \mathrm{m}$. Eixo equatorial: 59-70 $\mu \mathrm{m}$. Dados ecológicos: árvore de pequeno porte, decidual, pioneira, importante componente da vegetação secundária (Backes \& Irgang 2002).

\section{Família Fabaceae}

\section{Tipo Vicia L.}

Fig. 45-47

Prolato, radiossimétrico, isopolar. Elíptico-comprimido em vista equatorial. Tricolporado, psilado, levemente escabrado junto à região equatorial entre os colporos. Endoabertura grande e circular. Columelas evidentes. Eixo polar: 46-68 $\mu \mathrm{m}$. Eixo equatorial: $32-41 \mu \mathrm{m}$. Dados ecológicos: gênero com espécies nativas no Brasil, geralmente de porte baixo, trepadeiras com gavinhas, em campos, entremeadas a espécies herbáceas ou arbustivas, formando touceiras ou prostradas (N.R. Bastos, dados não publicados).

\section{Ordem Proteales \\ Família Proteaceae}

\section{Roupala Aubl.}

Fig. 48-49

Radiossimétrico, isopolar. Triangular em vista polar, com zonas interangulares retas. Triporado, escabrado. Poros desenvolvidos. Columelas evidentes. Eixo equatorial: 30-31 $\mu \mathrm{m}$. Dados ecológicos: gênero com espécies arbóreas, de ampla dispersão em matas do sul do Brasil (Backes \& Irgang 2002). Ocorre na mata com Araucária no Planalto do Rio Grande do Sul (Rambo 1956).

\section{Ordem Haloragales \\ Família Haloragaceae}

\section{Myriophyllum L.}

Fig. 50-52

Oblato-esferoidal, radiossimétrico, isopolar. Aproximadamente circular em vista polar e levemente elíptico em vista equatorial. Triporado a tetraporado, psilado a microverrucado, verrugas tênues. Poros muito salientes, com acentuado espessamento anelar. Columelas evidentes. Eixo polar: cerca de $36 \mu \mathrm{m}$. Eixo equatorial: 25-38 $\mu \mathrm{m}$. Dados ecológicos: ervas aquáticas ou de locais brejosos, distribuídas nas regiões temperadas, tropicais e subtropicais (Joly 2002; Fevereiro 1975).

\section{Ordem Myrtales \\ Família Lythraceae}

\section{Cuphea carunculata Koehne}

\section{Fig. 53-54}

Radiossimétrico, isopolar. Triangular em vista polar, zonas interangulares quase retas, levemente projetadas. Tricolpo- 
rado, psilado. Endoabertura com proeminência bem característica, perceptível em vista polar. Columelas nem sempre evidentes. Eixo equatorial: 26-31 $\mu \mathrm{m}$. Dados ecológicos: Cuphea é composto por ervas ou arbustos de campos úmidos ou secos, também em borda de mata, mata aberta, em clareiras ou mesmo em banhados (Lourteig 1969).

Família Myrtaceae

\section{Myrtaceae}

\section{Fig. 55}

Radiossimétrico, isopolar. Subtriangular a triangular em vista polar, com zonas interangulares retas a levemente convexas e ângulos arredondados. Tricolporado psilado. Colporos freqüentemente unidos na região do apocolpio, formando uma figura triangular. Columelas nem sempre evidentes. Eixo equatorial: 20-28 $\mu \mathrm{m}$. Dados ecológicos: família composta por espécies arbustivas ou arbóreas, com distribuição tropical ou subtropical (Schultz 1990). No Rio Grande do Sul é a família com o maior número de espécies na flora arbórea, também se destacando pela grande densidade em distintas formações florestais (Sobral 2003).

\section{Família Onagraceae}

\section{Ludwigia L.}

Fig. 56-57

Radiossimétrico, isopolar. Robusto. Subtriangular a aproximadamente triangular em vista polar. Tripororado, psilado a verrucado, com verrugas irregulares e tênues. Poros com característico espessamento anelar. Endoabertura muito desenvolvida, inflando a zona das aberturas. Columelas nem sempre evidentes. Eixo equatorial: 58-60 $\mu \mathrm{m}$. Dados ecológicos: ervas ou arbustos de ampla distribuição na América tropical, associados a locais úmidos, como brejos, terrenos alagadiços e margens de lagos (Schultz 1990; Joly 2002; Marchant et al. 2002; Souza \& Lorenzi 2005).

Família Melastomataceae

\section{Melastomataceae}

Fig. 58

Subprolato a prolato, radiossimétrico, isopolar. Pequeno. Circular em vista polar. Tricolporado, psilado, pseudocolpos intercalados aos colporos. Estratificação obscura. Eixo equatorial: 15-21 $\mu \mathrm{m}$. Dados ecológicos: plantas herbáceas, arbustivas ou arbóreas, distribuídas nas regiões tropicais e subtropicais, em campos, brejos e bordo das matas (Joly 2002; Souza \& Lorenzi 2005).

\section{Ordem Santalales \\ Família Loranthaceae}

\section{Phrygilanthus Eichler}

Fig. 59

Radiossimétrico, isopolar. Triangular em vista polar, com zonas interangulares côncavas e ângulos truncados. Exina com uma camada frouxa e hialina na região equatorial interangular, formada por projeções densamente distribuídas. Tricolporado, psilado, colporos unidos nos pólos. Eixo equatorial: 28-31 ìm. Dados ecológicos: hemiparasitas sobre plantas arbóreas (Schultz 1990). O gênero é citado para o Planalto do Rio Grande do Sul (Rambo 1956).

Ordem Celastrales

Família Aquifoliaceae

\section{Ilex L.}

Fig. 60-63

Suboblato a subprolato, radiossimétrico, isopolar. Circular a subtriangular em vista polar, elíptico em vista equatorial. Tricolporado, clavado. Clavas pequenas, densamente dispostas. Estratificação obscura. Eixo polar: cerca de $28 \mu \mathrm{m}$. Eixo equatorial: 22-35 $\mu \mathrm{m}$. Dados ecológicos: árvores ou arbustos distribuídos em zonas tropicais e temperadas. Ocorrentes no Planalto do Rio Grande do Sul, na encosta atlântica e na restinga litorânea (Edwin \& Reitz 1967).

Ordem Euphorbiales

Família Euphorbiaceae

\section{Alchornea triplinervia (Spreng.) Müll. Arg.} Fig. 64-65

Oblato-esferoidal a subprolato, radiossimétrico, isopolar. Circular em vista polar, elíptico em vista equatorial. Tricolporado, psilado, com opérculos alongados característicos nas aberturas. Columelas evidentes. Eixo polar: cerca de $29 \mu \mathrm{m}$. Eixo equatorial: 24-32 $\mu \mathrm{m}$. Dados ecológicos: árvore de grande porte, polimórfica, heliófita. Ampla distribuição, ocorrendo em quase todas as formações naturais em áreas abertas, clareiras ou matas alteradas. Indicada para a recuperação de vegetação secundária (Reitz et al. 1983; Schultz 1990; Backes \& Irgang 2002; Souza \& Lorenzi 2005).

\section{Tipo Croton L.}

Fig. 66-68

Esférico, radiossimétrico, apolar. Inaperturado, sexine com excrescências formando conjuntos concêntricos do tipo "padrão Croton" de escultura. Diâmetro: cerca de $52 \mu \mathrm{m}$. Observação: encontrado somente fragmentos de grão. Dados ecológicos: gênero de árvores, arbustos ou ervas, predominantemente tropicais, podendo ocorrer em campos, brejos ou pântanos (Schultz 1990; Smith et al. 1988; Marchant et al. 2002).

Ordem Polygalales

Família Polygalaceae

\section{Polygala $\mathrm{L}$.}

Fig. 69-70

Prolato, radiossimétrico, isopolar. Elíptico-comprimido em vista equatorial. Estefanocolporado, psilado. Colporos 

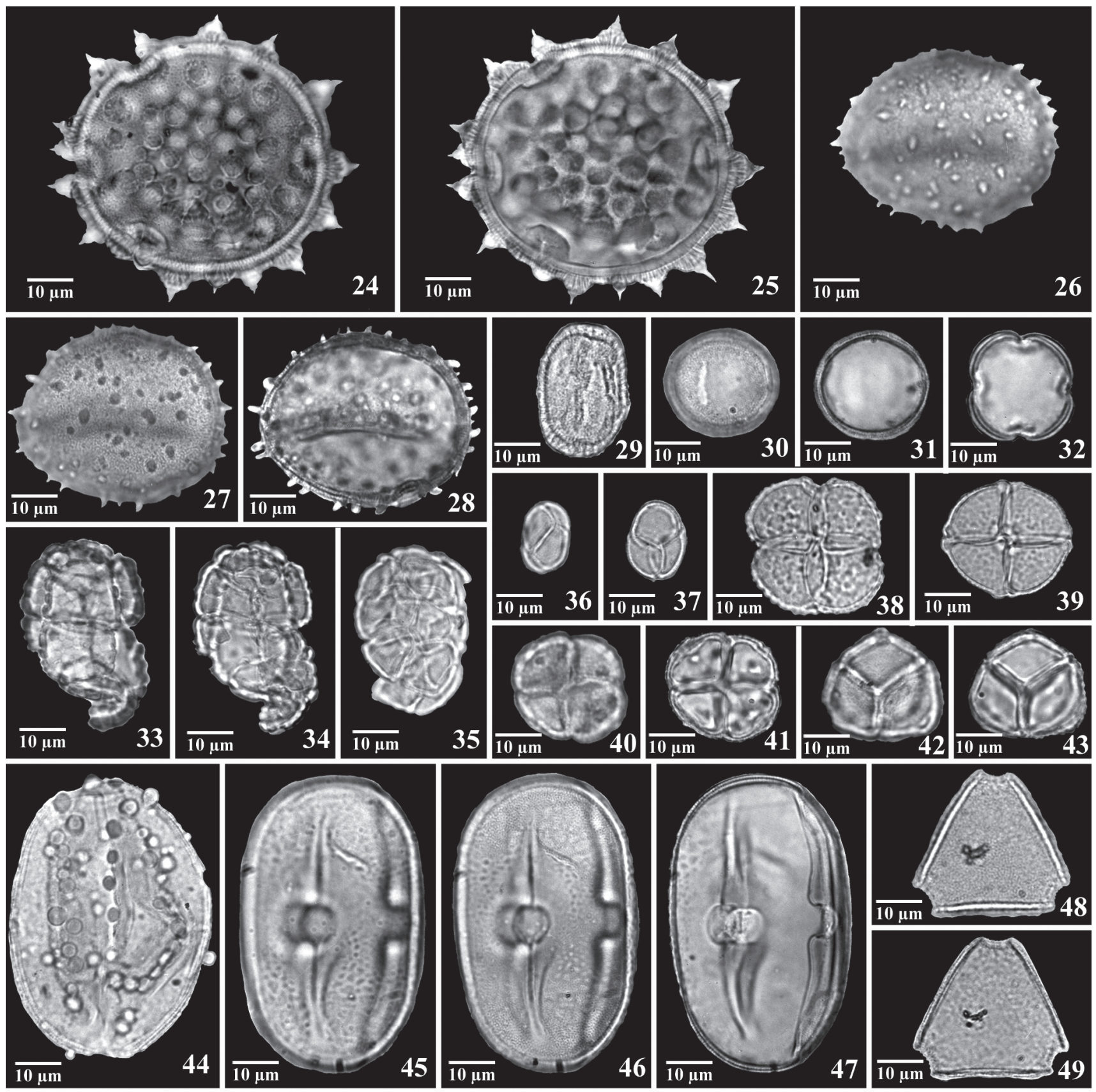

$4 0 \longdiv { 1 0 \mu \mathrm { m } }$
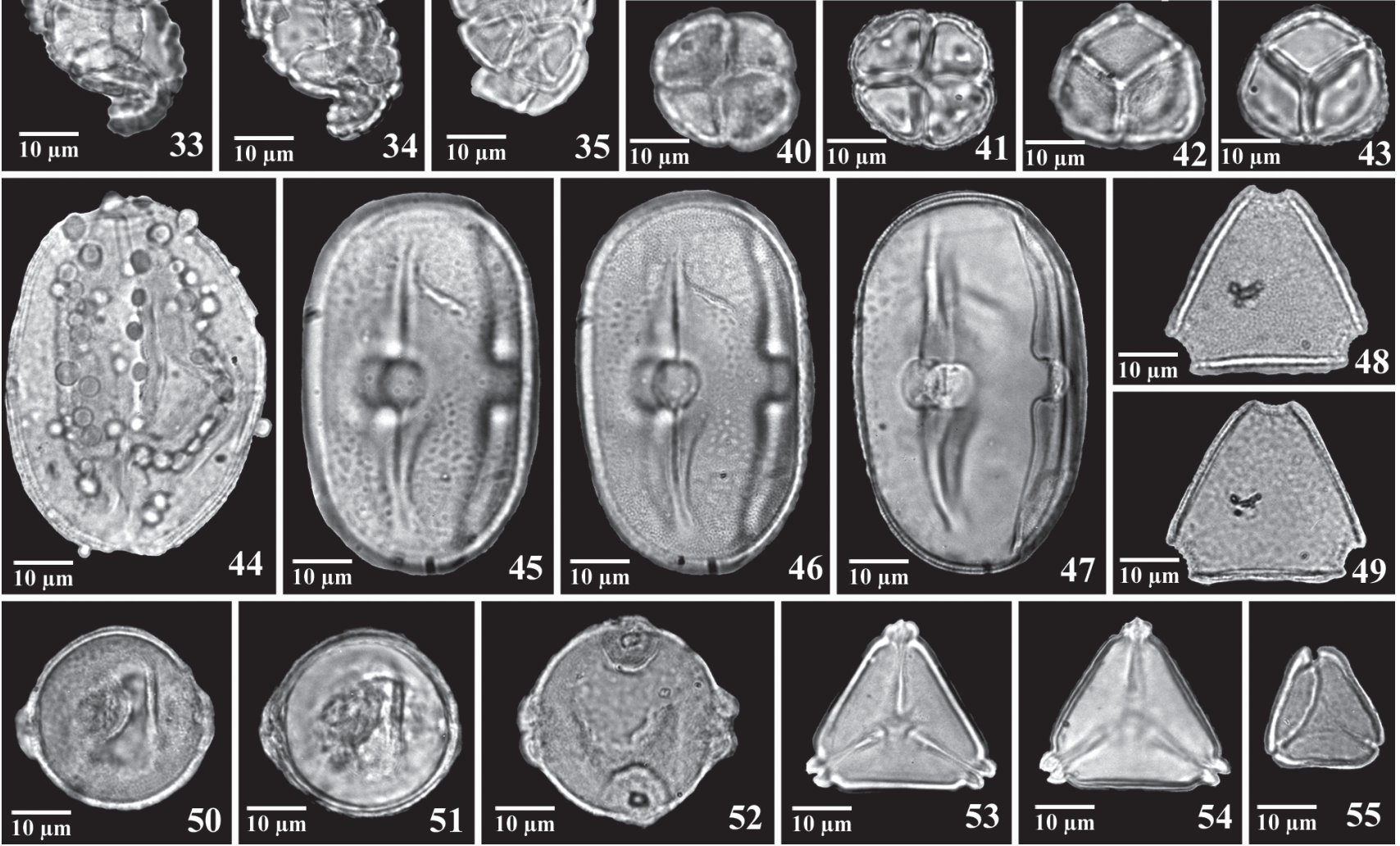

Figuras 24-55. Angiospermas. 24-25. Malvaceae: $1^{\circ}-2^{\circ} \mathrm{pl}$. 26-28. Cucurbitaceae: $1^{\circ}-3^{\circ} \mathrm{pl}$. 29. Chrysophyllum L. (EQ). $30-32$. Myrsine L. $30-31$. (EQ): $1^{\circ}-2^{\circ} \mathrm{pl}$, 32. (P). 33-34. Tipo Acacia Mill. 1 (fraturado): $1^{\circ}-2^{\circ}$ pl. 35. Tipo Acacia Mill. 2. 36-37. Mimosa scabrella Benth. 38-39. Mimosa ser. Lepidotae Benth. 40-41. Mimosa L. 1: $1^{\circ}-2^{\circ}$ pl. 42-43. Mimosa L. 2: $1^{\circ}-2^{\circ}$ pl. 44. Bauhinia forficata subsp. pruinosa (Vogel) Fortunato \& Wunderlin (oblíquo). 45-47. Tipo Vicia L. (EQ): $1^{\circ}-3^{\circ}$ pl. $48-49$. Roupala Aubl. (P): $1^{\circ}-2^{\circ}$ pl. 50-52. Myriophyllum L. 50-51. (EQ): $1^{\circ}-2^{\circ}$ pl. 52. (oblíquo). 53-54. Cuphea carunculata Koehne (P): $1^{\circ}-2^{\circ}$ pl. 55. Myrtaceae $(\mathrm{P}) .(\mathrm{pl}=$ planos, $\mathrm{P}=$ vista polar, $\mathrm{EQ}=$ vista equatorial $)$. 
longos e estreitos, endoaberturas largas, unidas lateralmente, formando uma faixa contínua na região equatorial. Columelas pouco evidentes. Eixo polar: 27-33 $\mu \mathrm{m}$. Eixo equatorial: 16-24 $\mu \mathrm{m}$. Dados ecológicos: ervas ou subarbustos, anuais, bianuais ou perenes, de ampla distribuição. Encontrados em campos, capoeiras, banhados, turfeiras, matas de pinhais, matinha nebular, bordas de mata, dunas, topos de morros e na margem de estrada, em solos secos, úmidos ou pedregosos (Lüdtke \& Miotto 2004).

Ordem Sapindales

Família Sapindaceae

36. Allophylus edulis (A. St.-Hil., Cambess. \& A. Juss.) Radlk.

Fig. 71

Radiossimétrico, isopolar. Quadrangular em vista polar, zonas interangulares retas a levemente convexas. Tetraporado, per-reticulado, retículo muito fino. Estratificação obscura. Eixo equatorial: 29-34 $\mu \mathrm{m}$. Dados ecológicos: pioneira de pequeno porte (Backes \& Irgang 2002), ocorrendo no interior e borda de matas, capões, capoeiras e beira de rios (Reitz 1980; Schultz 1990), como também na mata com Araucária.

\section{Sapindaceae}

Fig. 72-73

Radiossimétrico, isopolar. Triangular em vista polar, zonas interangulares retas a levemente côncavas. Tricolporado, per-reticulado, retículo fino. Colporos unidos na região do apocolpio, formando uma figura triangular. Columelas pouco evidentes. Eixo equatorial: 34-45 $\mu \mathrm{m}$. Dados ecológicos: plantas trepadeiras com gavinhas, também arbustos e árvores, raramente ervas, distribuição tropical e subtropical (Reitz 1980; Schultz 1990; Joly 2002; Souza \& Lorenzi 2005).

Família Anacardiaceae

38. Anacardiaceae

Fig. 74-75

Prolato, radiossimétrico, isopolar. Elíptico em vista equatorial. Tricolporado, per-reticulado-estriado. Colporos longos, endoaberturas alongadas transversalmente, em geral levemente retangulares. Columelas evidentes sustentando o muro. Eixo polar: $36-49 \mu \mathrm{m}$. Eixo equatorial: 23-26 $\mu \mathrm{m}$. Dados ecológicos: árvores ou arbustos, raramente lianas ou ervas (Joly 2002; Souza \& Lorenzi 2005), predominante nas regiões tropicais e subtropicais. Em ambientes variados, interior ou borda de matas pouco densas, capões, margem de riachos, encostas de morros e campos alterados (Fleig 1987).

Família Meliaceae

39. Tipo Meliaceae

Fig. 76-77
Radiossimétrico, isopolar, aproximadamente quadrangular em vista polar. Tetracolporado, per-reticulado, retículo muito fino. Columelas evidentes. Eixo equatorial: 25-34 $\mu \mathrm{m}$. Dados ecológicos: família com espécies arbóreas de grande porte ou arbustos, em geral em florestas (Schultz 1990; Marchant et al. 2002), com distribuição predominantemente tropical e subtropical. Poucas espécies chegando até o sul do Brasil, em interior e borda de matas (Girardi 1975; Joly 2002).

Ordem Apiales

Família Apiaceae

\section{Eryngium L.}

Fig. 78

Perprolato, radiossimétrico, isopolar. Elíptico a elípticocomprimido em vista equatorial. Tricolporado, psilado, colporos longos. Endoaberturas alongadas transversalmente, retangulares. Columelas evidentes. Eixo polar: 27-41 $\mu \mathrm{m}$. Eixo equatorial: 10-18 $\mu \mathrm{m}$. Dados ecológicos: ervas anuais ou perenes (Irgang 1974; Schultz 1990; Joly 2002). Gênero cosmopolita, ocorrendo em capoeiras, campos, locais encharcados, pântanos, lagoas e turfeiras. No Rio Grande do Sul está presente principalmente nos Aparados da Serra e Campos de Cima da Serra (Irgang 1974).

Subclasse Asteridae
Ordem Lamiales
Família Verbenaceae

\section{Verbena L.}

Fig. 79-80

Subprolato a prolato, radiossimétrico, isopolar. Tricolporado, psilado. Colporos com margem levemente espessada. Columelas evidentes. Eixo polar: 47-49 $\mu \mathrm{m}$. Eixo equatorial: 34-41 $\mu \mathrm{m}$. Dados ecológicos: ervas campestres, comuns no Rio Grande do Sul (Schultz 1990).

\section{Família Lamiaceae}

\section{Lamiaceae}

Fig. 81-83

Radiossimétrico, isopolar. Aproximadamente circular em vista polar. Estefanocolpado, per-reticulado, em geral com seis colpos. Retículo fino. Columelas evidentes, sustentando o muro. Eixo equatorial: 26-28 $\mu \mathrm{m}$. Dados ecológicos: ervas anuais ou perenes, arbustos ou raramente árvores, ocorrendo em ambientes variados. Cosmopolita, com o maior centro de dispersão na região do Mediterrâneo e no Oriente (Schultz 1990; Harley 1985; Joly 2002; Souza \& Lorenzi 2005).

Ordem Plantaginales

Família Plantaginaceae

\section{Plantago L.}

Fig. 84-86 
Esférico, radiossimétrico, apolar. Pantoporado, verrucado. Poros tênues e distanciados. Verrugas delicadas. Columelas evidentes. Diâmetro: 27-30 $\mu \mathrm{m}$. Dados ecológicos: plantas herbáceas campestres ou ruderais. Cosmopolitas, preferencialmente em zonas temperadas e frias, em terrenos arenosos da restinga, campos secos a pantanosos, banhados e turfeiras (Rahn 1966; Schultz 1990; Joly 2002).

Ordem Scrophulariales

Família Scrophulariaceae

44. Tipo Scrophulariaceae

Fig. 87-88

Subprolato, radiossimétrico, isopolar. Pequeno e hialino. Subtriangular em vista polar, levemente elíptico em vista equatorial. Tricolporado, psilado. Estratificação pouco evidente. Eixo polar: 10-13 $\mu \mathrm{m}$. Eixo equatorial: 8-10 $\mu \mathrm{m}$. Dados ecológicos: espécies herbáceas ou subarbustivas, mais raramente arbóreas. Cosmopolitas, centro de dispersão nas zonas temperadas. No Brasil com várias espécies campestres ou ruderais (Ichaso \& Barroso 1970; Schultz 1990; Joly 2002).

\section{Família Bignoniaceae}

\section{Bignoniaceae}

Fig. 89-90

Radiossimétrico, isopolar. Robusto. Circular a subtriangular em vista polar, com zonas interangulares levemente convexas. Tricolpado, per-reticulado, retículo de tamanho variável. Columelas evidentes, sustentando o muro. Eixo equatorial: 41-45 $\mu \mathrm{m}$. Dados ecológicos: plantas arbóreas, arbustivas e também trepadeiras com gavinhas foliares, raramente herbáceas (Sandwith \& Hunt 1974; Schultz 1990; Joly 2002; Souza \& Lorenzi 2005). Ampla distribuição nas regiões tropicais, poucas espécies nas zonas temperadas (Schultz 1990; Joly 2002).

\section{Família Lentibulariaceae}

\section{Utricularia L.}

Fig. 91

Radiossimétrico, isopolar. Aproximadamente circular em vista polar. Estefanocolporado, psilado, endoaberturas unidas. Estratificação obscura. Eixo equatorial: cerca de $29 \mu \mathrm{m}$. Dados ecológicos: pequenas ervas heliófitas e higrófitas seletivas, ocorrendo preferencialmente sobre solos rochosos úmidos, lagoas, lagos, represas, banhados rasos e turfeiras (Schultz 1990; Joly 2002), com utrículos apropriados para captura e absorção da microfauna aquática (Taylor 1980; Souza \& Lorenzi 2005).

\section{Ordem Rubiales}

Família Rubiaceae

\section{Tipo Galium L.}

Fig. 92-93
Radiossimétrico, isopolar. Circular em vista polar. Estefanocolporado, psilado. Columelas evidentes. Eixo equatorial: 24-27 $\mu \mathrm{m}$. Obs: citado anteriormente para o Quaternário do Rio Grande do Sul pelo antigo nome de Relbunium (Endl.) Hook. f. Dados ecológicos: gênero composto por ervas anuais ou perenes, trepadeiras, muito raramente subarbustos, eretos ou escandentes, de locais úmidos (Joly 2002; Delprete et al. 2004). Amplamente distribuído no Rio Grande do Sul (Porto \& Mariath 1975) em ambientes variados, campos úmidos, capoeiras, turfeiras, banhados, borda de capões ou margens de rios (Delprete et al. 2004).

\section{Tipo Richardia L.}

Fig. 94-99

Oblato a subprolato, radiossimétrico, isopolar. Robusto. Circular em vista polar. Estefanocolporado, per-reticulado. Colporos longos. Endoaberturas conspícuas. Columelas evidentes. Eixo polar: cerca de $43 \mu \mathrm{m}$. Eixo equatorial: 35-63 $\mu \mathrm{m}$. Observação: primeira citação para o Quaternário do Rio Grande do Sul. Dados ecológicos: ervas anuais ou perenes ou subarbustos, de distribuição na América tropical. Ocorrentes em campos, capoeiras, terrenos baldios ou como espécies ruderais (Joly 2002; Delprete et al. 2005).

\section{Rubiaceae}

Fig. 100-102

Subprolato, radiossimétrico, isopolar. Elíptico em vista equatorial. Estefanocolporado, per-reticulado. Colporos longos. Estratificação evidente. Eixo polar: cerca de $39 \mu \mathrm{m}$. Eixo equatorial: 31-63 $\mu \mathrm{m}$. Dados ecológicos: árvores, arbustos, ervas eretas ou rastejantes, trepadeiras volúveis herbáceas ou lenhosas, ou lianas, terrícolas ou raramente epifíticas (Schultz 1990; Joly 2002; Delprete et al. 2004). Cosmopolita, especialmente em zonas tropicais e subtropicais, com poucas espécies em zonas temperadas (Joly 2002).

\section{Ordem Dipsacales \\ Família Valerianaceae}

50. Valeriana eichleriana (C. Muell.) Graebn. Fig. 103-104

Esférico, radiossimétrico, apolar. Pantoporado, psilado, poros pequenos, distanciados. Columelas evidentes. Diâmetro: cerca de $44 \mu \mathrm{m}$. Dados ecológicos: erva comum nos campos rupestres de altitude e na floresta nebular (Sobral 1999).

\section{Valeriana L.}

Fig. 105-109

Suboblato a prolato-esferoidal, radiossimétrico, isopolar. Circular em vista polar, circular a levemente elíptico em vista equatorial. Tricolpado, microequinado. Colpos longos. Espinhos finos, distanciados, regularmente distribuídos. Columelas evidentes. Eixo polar: 29-35 $\mu \mathrm{m}$. Eixo equatorial: 

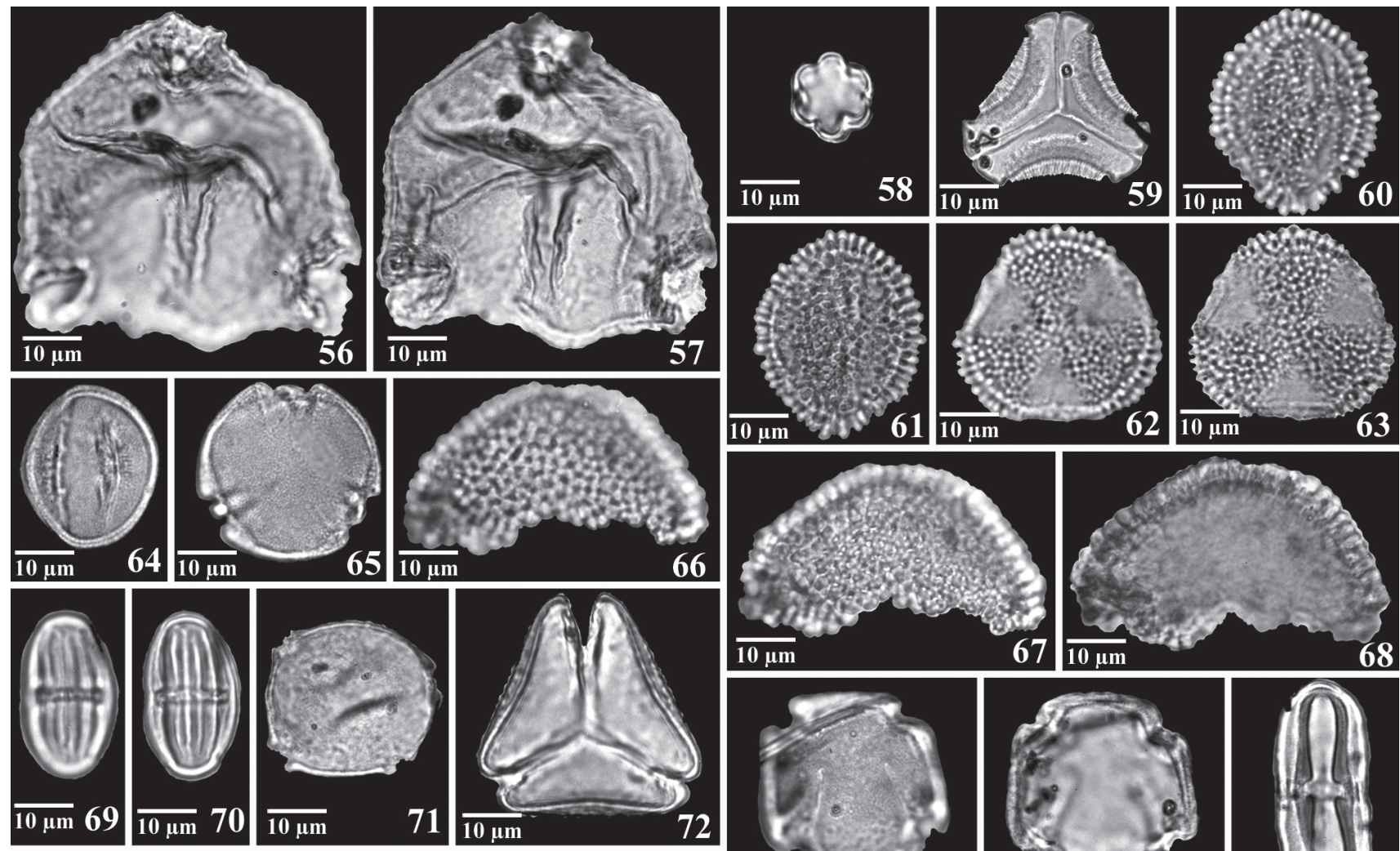

66
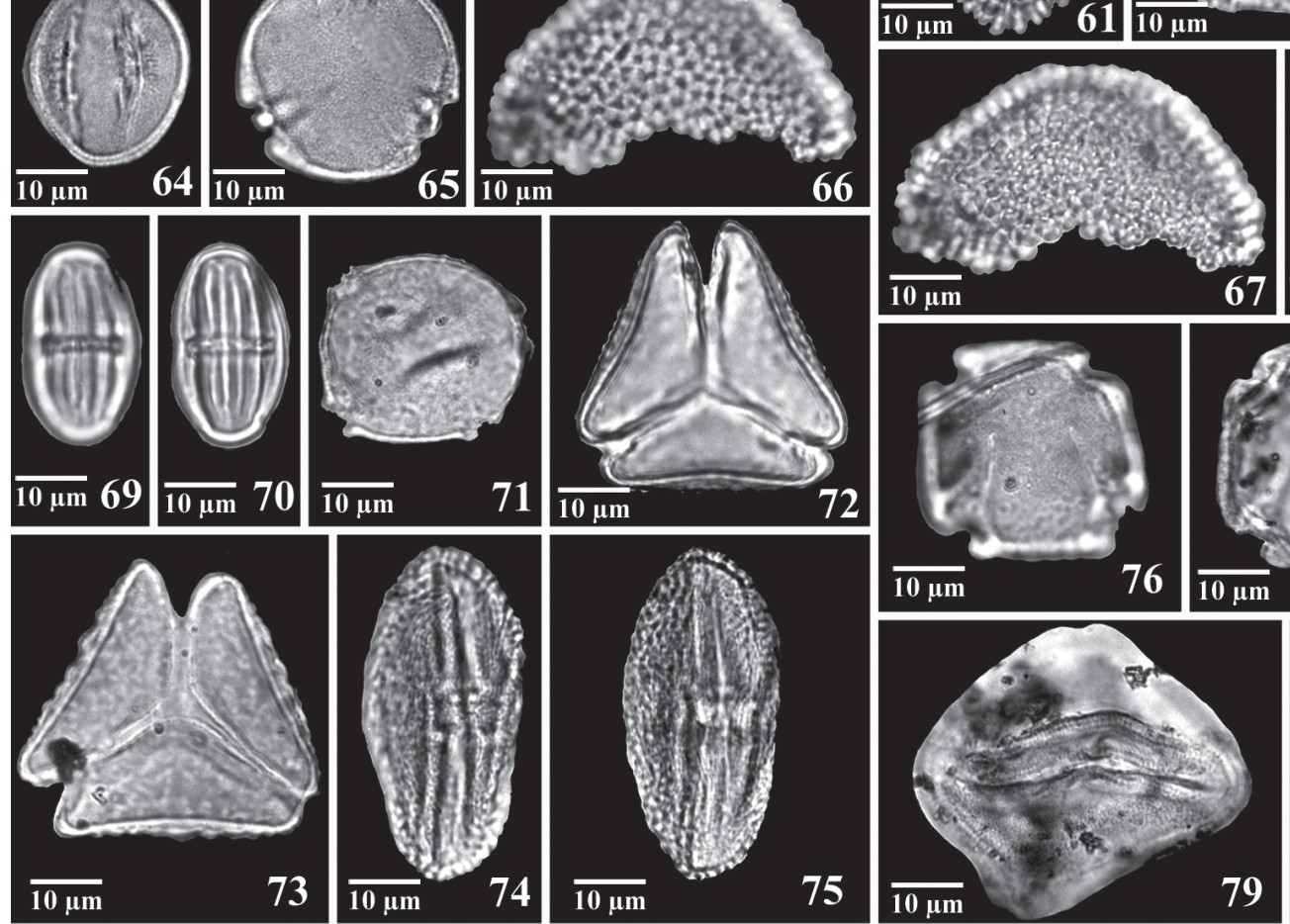

62
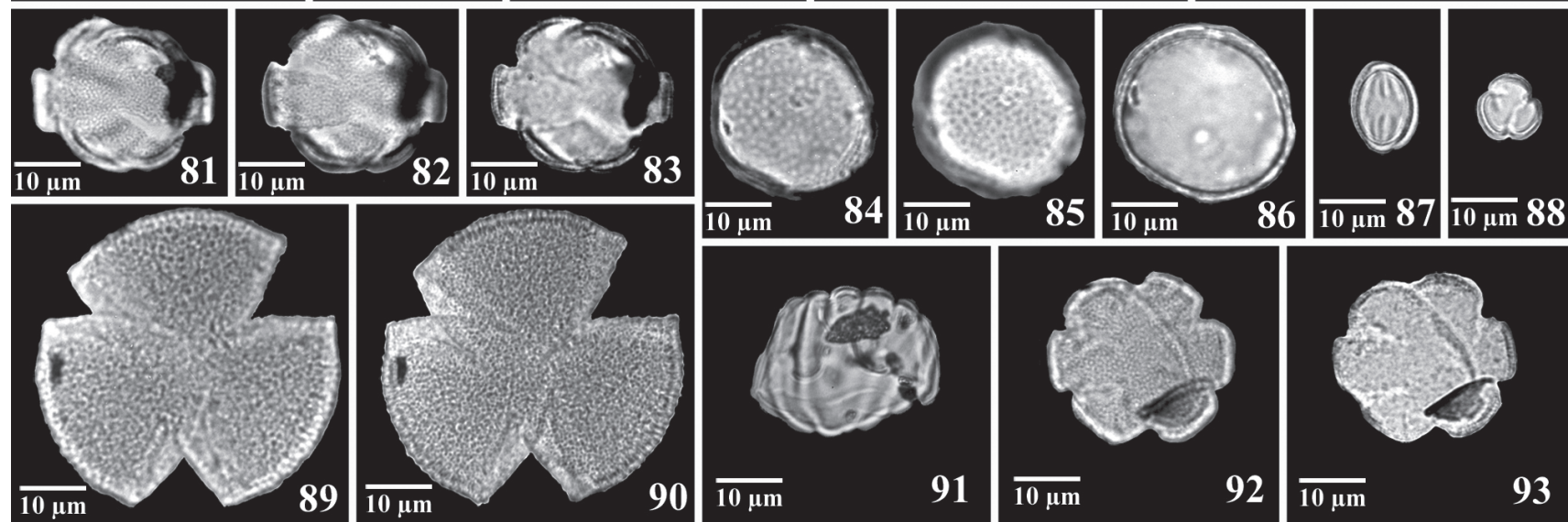

Figuras 56-93. Angiospermas. 56-57. Ludwigia L. (P): $1^{\circ}-2^{\circ}$ pl. 58. Melastomataceae (P). 59. Phrygilanthus Eichler (P). 60-63. Ilex L. 60-61. (EQ): $1^{\circ}-2^{\circ}$ pl, 62-63. (P): $1^{\circ}-2^{\circ}$ pl. 64-65. Alchornea triplinervia (Spreng.) Müll. Arg. 64. (EQ). 65. (P). 66-68. Tipo Croton L. (fragmentado): $1^{\circ}-3^{\circ}$ pl. 69-70. Polygala L (EQ): $1^{\circ}-2^{\circ}$ pl. 71. Allophylus edulis (A. St.-Hil., Cambess. \& A. Juss.) Radlk. (P). 72-73. Sapindaceae (P, fraturado). 74-75. Anacardiaceae (EQ): $1^{\circ}-2^{\circ} \mathrm{pl} .76-77$. Tipo Meliaceae (P): $1^{\circ}-2^{\circ}$ pl. 78. Eryngium L. (EQ). 79-80. Verbena L. (oblíquo): $1^{\circ}-2^{\circ}$ pl. 81-83. Lamiaceae (oblíquo): $1^{\circ}-3^{\circ}$ pl. 84-86. Plantago L.: $1^{\circ}-3^{\circ} \mathrm{pl}$. 87-88. Tipo Scrophulariaceae. 87. (EQ). 88. (P). 89-90. Bignoniaceae (P): $1^{\circ}-2^{\circ}$ pl. 91. Utricularia L. (oblíquo). 92-93. Tipo Galium L. (P): $1^{\circ}-2^{\circ}$ pl. $(\mathrm{pl}=$ planos, $\mathrm{P}=$ vista polar, $\mathrm{EQ}=$ vista equatorial $)$. 
26-40 $\mu \mathrm{m}$. Dados ecológicos: ervas ou arbustos, raro trepadeiras. Ampla distribuição no Rio Grande do Sul, em campos de altitude, matas com Araucária, matas de galeria, matas nebulares e banhados (Sobral 1999).

Ordem Asterales

Família Asteraceae

\section{Tipo Baccharis L.}

Fig. 110-112

Suboblato a prolato, radiossimétrico, isopolar. Circular em vista polar, circular a elíptico em vista equatorial. Tricolporado, equinado. Espinhos robustos, regularmente distribuídos, podendo mascarar as aberturas. Columelas evidentes. Freqüentemente com descolamento da nexina, formando cava abaixo das columelas. Eixo polar: cerca de $29 \mu \mathrm{m}$. Eixo equatorial: 19-36 $\mu \mathrm{m}$. Dados ecológicos: gênero de espécies herbáceas e arbustivas, em campos. Pode ocorrer também em áreas intermediárias entre campo e a mata, com vegetação arbustiva (Joly 2002), ou ainda em áreas entre pântano herbáceo e mata paludosa. Com várias espécies ocorrentes nos campos do Planalto do Rio Grande do Sul (Rambo 1956).

\section{Tipo Gnaphalium L.}

Fig. 113

Esférico, radiossimétrico, isopolar. Circular em vista polar e equatorial. Tricolporado, microequinado. Espinhos regularmente dispostos sobre toda a superfície. Estratificação obscura. Eixo polar: cerca de $22 \mu \mathrm{m}$. Eixo equatorial: cerca de $22 \mu \mathrm{m}$. Dados ecológicos: gênero de ervas comuns na região litorânea e em terrenos alterados (Joly 2002). Presentes nos campos do Planalto do Rio Grande do Sul (Rambo 1956).

\section{Tipo Vernonia Schreb.}

Fig. 114-115

Esférico, radiossimétrico, isopolar. Tricolporado perreticulado, equinolofado. Retículo grosseiro com muros muito altos portando espinhos robustos, regularmente distribuídos, mascarando as aberturas. Diâmetro: 28-55 $\mu \mathrm{m}$. Dados ecológicos: gênero de ervas, subarbustos, arbustos e árvores. Ampla representação de espécies no Rio Grande do Sul, ocorrendo em campos, banhados, capoeiras, beira e interior de matas e margem de rios, também como ruderais (Matzenbacher \& Mafioleti 1994).

\section{Mutisieae 1}

Fig. 116-117

Subprolato a prolato, radiossimétrico, isopolar. Robusto. Elíptico-fusiforme em vista equatorial, com pólos levemente projetados. Tricolporado, psilado. Colporos longos. Exina biestratificada, columelas evidentes. Camada interna de columelas mais espessa na zona equatorial. Eixo polar: 53-56 $\mu \mathrm{m}$. Eixo equatorial: 39-43 $\mu \mathrm{m}$. Observação: possíveis espinhos diminutos não puderam ser observados. Dados ecológicos: tribo representada por ervas e arbustos, menos freqüentemente lianas e árvores. Maioria das espécies ocorrendo em ambientes campestres (C.A. Mondin, dados não publicados).

\section{Mutisieae 2}

Fig. 118-119

Prolato-esferoidal, radiossimétrico, isopolar. Aproximadamente circular em vista equatorial. Tricolporado, psilado. Exina biestratificada, columelas evidentes. Eixo polar: cerca de $43 \mu \mathrm{m}$. Eixo equatorial: cerca de $38 \mu \mathrm{m}$. Obs: as diferenças entre Mutisieae 1 e Mutisieae 2 são a forma dos grãos e a distribuição das columelas. Dados ecológicos: como em Mutisieae 1.

\section{Classe Liliopsida \\ Subclasse Alismatidae \\ Ordem Alismatales \\ Família Alismataceae}

\section{Alismataceae}

Fig. 120-122

Esférico, radiossimétrico, apolar. Pantoporado, microequinado. Poros tênues e distanciados. Espinhos também distanciados, regularmente distribuídos, muito finos. Columelas evidentes. Diâmetro: 29-32 m. Dados ecológicos: plantas herbáceas lactescentes, cosmopolitas, aquáticas ou palustres (Schultz 1990; Joly 2002; Souza \& Lorenzi 2005). No Rio Grande do Sul ocorrem espécies submersas, flutuantes e emersas, habitando campos úmidos, banhados, bordas de lagos e rios (Irgang \& Gastal Junior 1996).

\section{Subclasse Commelinidae \\ Ordem Eriocaulales \\ Família Eriocaulaceae}

\section{Eriocaulaceae}

Fig. 123-125

Oblato, radiossimétrico, isopolar. Espiraperturado, microequinado. Espinhos distanciados, regularmente distribuídos. Columelas evidentes. Eixo polar: cerca de $20 \mu \mathrm{m}$. Eixo equatorial: cerca de $27 \mu \mathrm{m}$. Observação: encontrado geralmente em fragmentos nas amostras. Dados ecológicos: plantas herbáceas, heliófitas e higrófitas seletivas, em zonas tropicais e subtropicais, com centro de maior dispersão na região tropical da América do Sul, especialmente Brasil (Joly 2002). Em locais arenosos e úmidos, como também em banhados (Moldenke \& Smith 1976; Schultz 1990).

\section{Ordem Cyperales \\ Família Cyperaceae}

\section{Cyperaceae}

Fig. 126 
Subprolato a prolato, radiossimétrico, heteropolar. Pólo distal em geral alargado, afilando em direção ao pólo proximal. Inaperturado, monoulcerado e/ou com aberturas alongadas e irregulares, em número variável, na região equatorial. Escabrado, com ornamentação mais grosseira nas aberturas. Columelas nem sempre evidentes. Eixo polar: 37-48 $\mu \mathrm{m}$. Eixo equatorial: 20-41 $\mu \mathrm{m}$. Observação: pólen freqüentemente dobrado devido à fina espessura da exina. Dados ecológicos: plantas cosmopolitas. Herbáceas, em locais abertos e úmidos, mas também em ambientes mais secos (Schultz 1990; Joly 2002; Souza \& Lorenzi 2005).

Família Poaceae

60. Poaceae

Fig. 127-132

Oblato-esferoidal a esférico, radiossimétrico, heteropolar. Circular em vista polar e equatorial. Monoporado, psilado a levemente escabrado, poro com espessamento anelar. Columelas evidentes. Eixo polar: cerca de $47 \mu \mathrm{m}$. Eixo equatorial: cerca de $48 \mu \mathrm{m}$. Observação: pólen freqüentemente dobrado devido à fina espessura da exina. Dados ecológicos: espécies, a maioria herbáceas, anuais ou perenes, predominando em áreas abertas de campo. Em variados ambientes no Rio Grande do Sul (Boldrini et al. 2005).

$$
\begin{aligned}
& \text { Ordem Typhales } \\
& \text { Família Typhaceae }
\end{aligned}
$$

\section{Typha L.}

\section{Fig. 133-134}

Radiossimétrico, heteropolar. Aproximadamente circular em vista polar. Monoulcerado, per-reticulado-rugulado. Columelas evidentes. Eixo equatorial: 30-40 $\mu \mathrm{m}$. Dados ecológicos: plantas herbáceas aquáticas, perenes, de distribuição cosmopolita. Em ambientes palustres ou lacustres, formando densos agrupamentos (Reitz 1984; Schultz 1990; Joly 2002).

\section{Subclasse Liliidae \\ Ordem Liliales \\ Família Pontederiaceae}

\section{Tipo Eichhornia Kunth}

Fig. 135

Peroblato, bilateral, heteropolar. Plano-convexo em vista equatorial. Bissulculado, psilado. Estratificação obscura. Eixo equatorial maior: cerca de $35 \mu \mathrm{m}$. Eixo equatorial menor: cerca de $15 \mu \mathrm{m}$. Dados ecológicos: gênero de ervas paludosas ou aquáticas, flutuantes ou emergentes, comuns em rios, riachos e lagos (Schultz 1990; Souza \& Lorenzi 2005).

\section{Família Liliaceae}

\section{Tipo Liliaceae 1}

Fig. 136-137

Oblato, elipsoidal, bilateral e heteropolar. Monossulcado, per-reticulado, retículo muito fino. Sulco longo. Columelas evidentes, sustentando o muro. Eixo equatorial maior: cerca de $44 \mu \mathrm{m}$. Eixo equatorial menor: 21-25 $\mu \mathrm{m}$. Dados ecológicos: família de plantas geralmente herbáceas, perenes, cosmopolitas, em diversos tipos de ambientes (Schultz 1990; Joly 2002).

\section{Tipo Liliaceae 2}

Fig. 138-139

Oblato, elipsoidal, bilateral e heteropolar. Robusto. Monossulcado per-reticulado. Sulco longo. Columelas evidentes, sustentando o muro. Eixo equatorial maior: 55-63 $\mu \mathrm{m}$. Eixo equatorial menor: 35-38 $\mu \mathrm{m}$. Observação: Tipo Liliaceae 2 difere do Tipo Liliaceae 1 pelo tamanho do pólen e dos lumens do retículo. Dados ecológicos: como em Tipo Liliaceae 1.

Grãos de pólen indeterminados

\section{Estefanocolpado}

Fig. 140-141

Esférico, amarronzado, radiossimétrico e isopolar. Estefanocolpado, per-reticulado. Nexina grossa e teto fino. Columelas evidentes. Eixo polar: cerca de $27 \mu \mathrm{m}$. Eixo equatorial: cerca de $27 \mu \mathrm{m}$.

\section{Tricolporado 1}

Fig. 142

Subprolato a prolato, radiossimétrico, isopolar. Elíptico em vista equatorial. Tricolporado, per-reticulado. Colporos longos, retículo grosseiro. Columelas evidentes, sustentando o muro. Sexina nitidamente mais espessa que a nexina, afilando acentuadamente nos pólos. Eixo polar: 29-31 $\mu \mathrm{m}$. Eixo equatorial: $21-24 \mu \mathrm{m}$.

\section{Tricolporado 2}

Fig. 143-144

Prolato, radiossimétrico, isopolar. Elíptico em vista equatorial. Tricolporado, per-reticulado. Colporos longos, endoaberturas unidas, retículo fino. Columelas evidentes. Eixo polar: cerca de $63 \mu \mathrm{m}$. Eixo equatorial: cerca de $39 \mu \mathrm{m}$.

\section{Triporado verrucado}

Fig. 145

Radiossimétrico, isopolar, aproximadamente circular em vista polar. Triporado, verrucado. Eixo equatorial: cerca de $37 \mu \mathrm{m}$. 

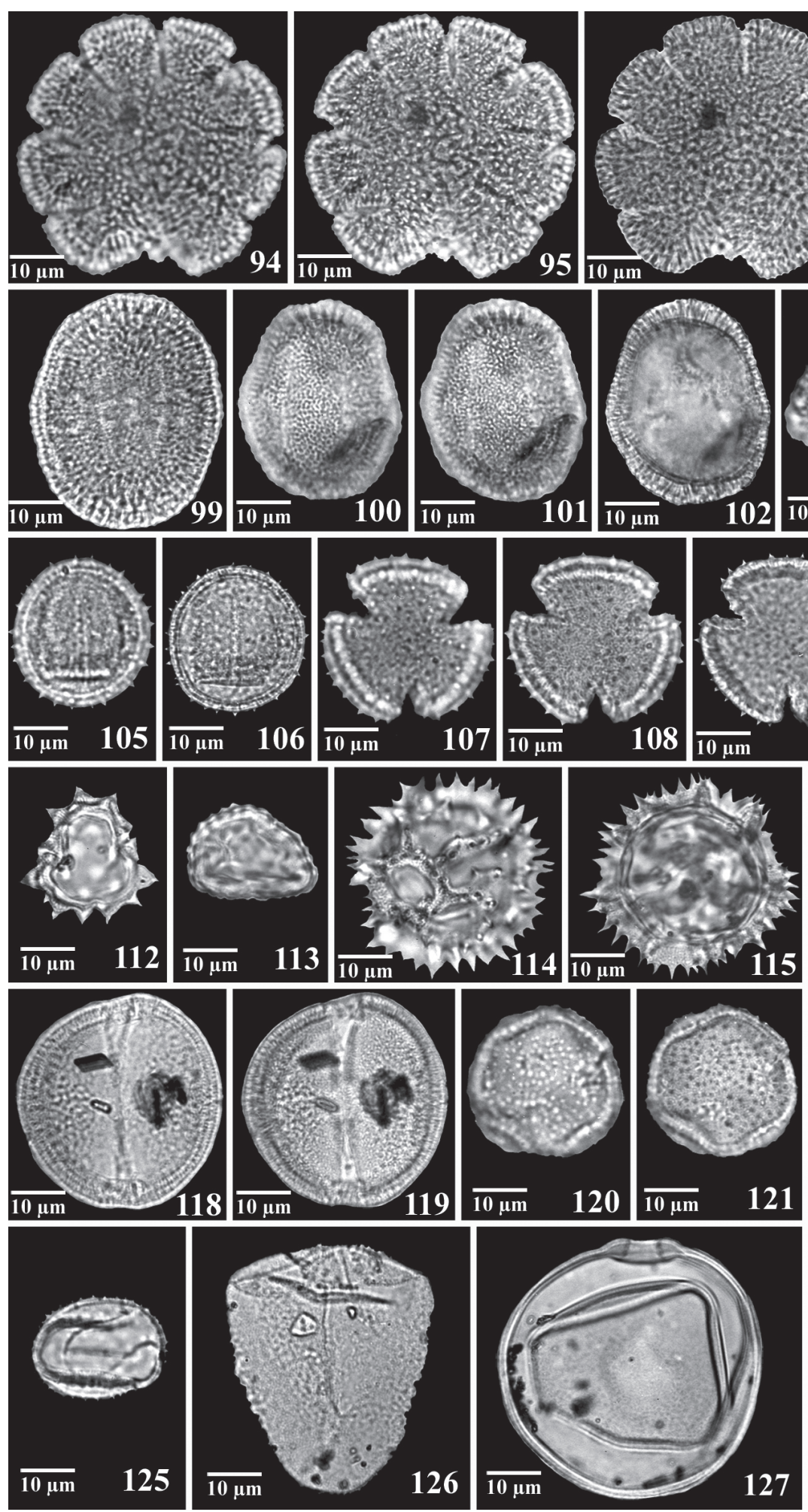

$\overline{10 \mu \mathrm{m}} \quad 112$
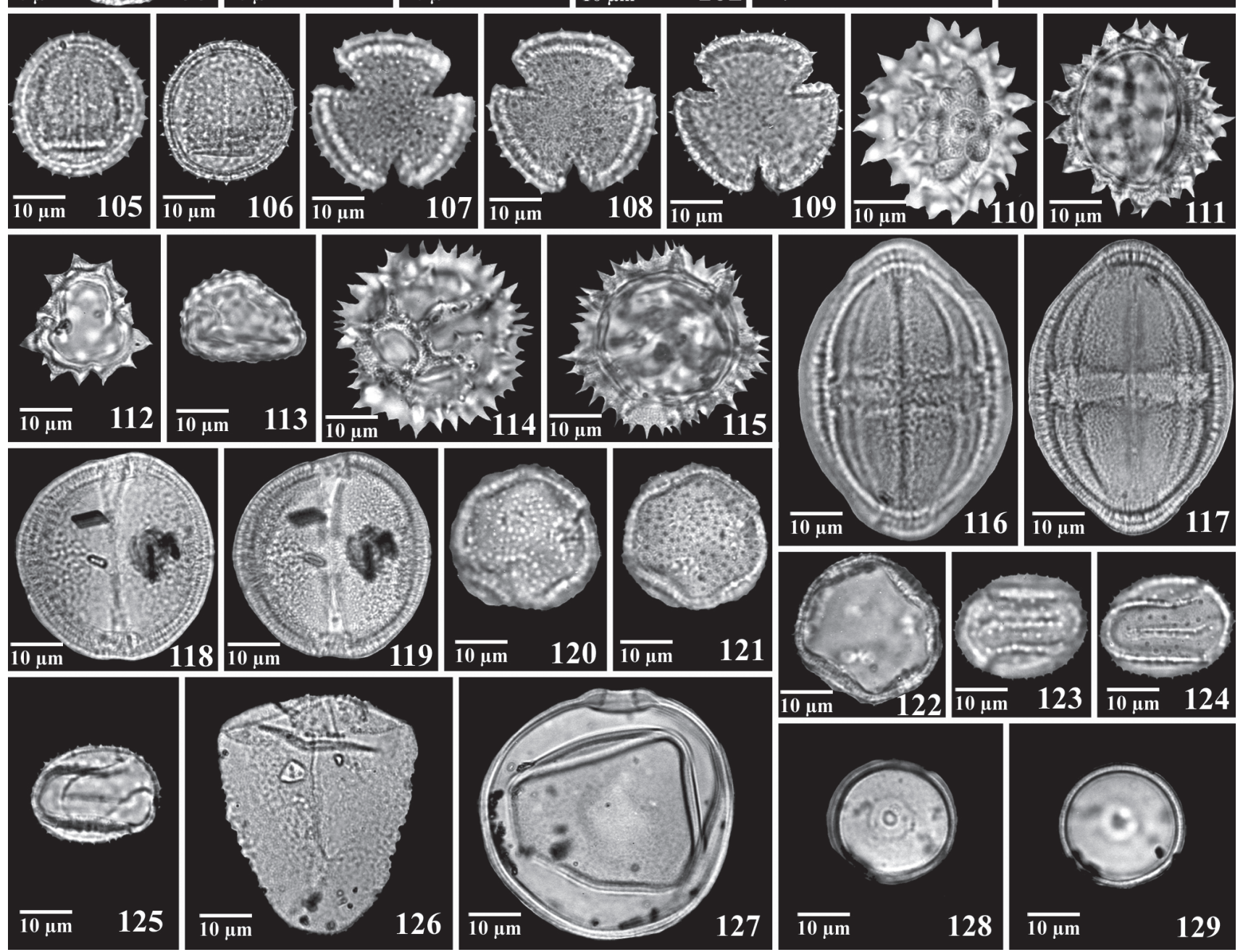

97
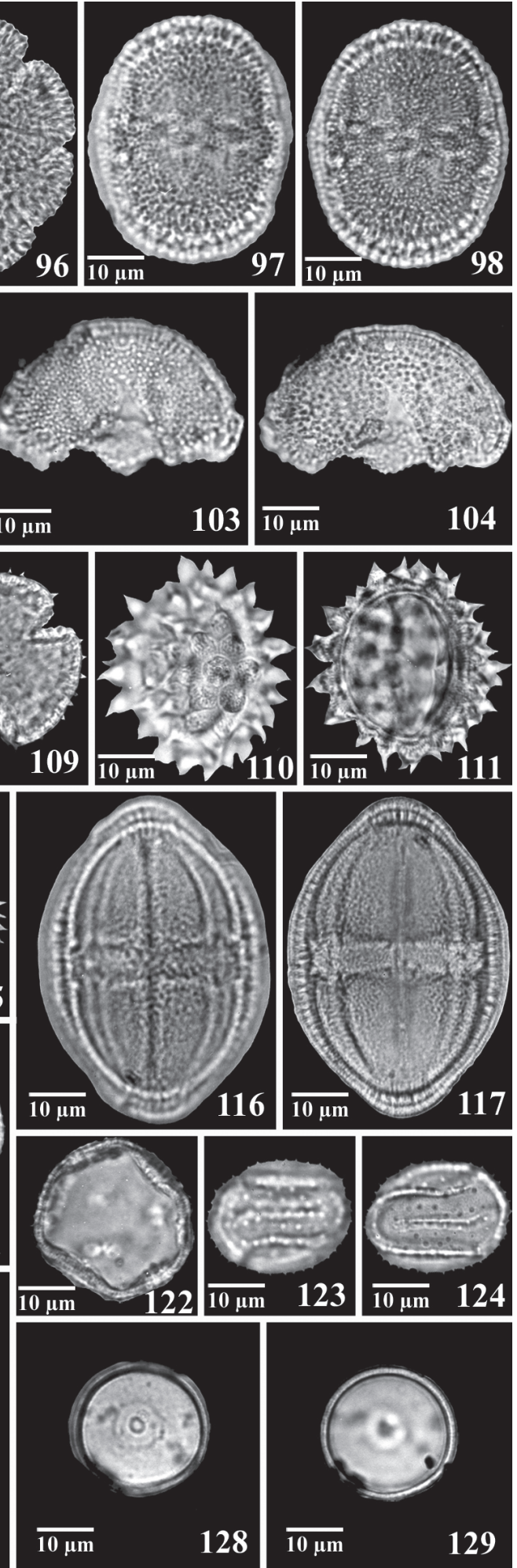

Figuras 94-129. Angiospermas. 94-99. Tipo Richardia L. 94-96. (P): $1^{\circ}-3^{\circ} \mathrm{pl}$. 97-99. (EQ): $1^{\circ}-3^{\circ} \mathrm{pl} .100-102$. Rubiaceae (EQ): $1^{\circ}-3^{\circ} \mathrm{pl} .103-104$. Valeriana eichleriana (C. Muell.) Graebn. (fragmentado, columelas vistas por transparência): $1^{\circ}-2^{\circ}$ pl. 105-109. Valeriana L. 105-106. (EQ): $1^{\circ}-2^{\circ}$ pl. $107-109$. (P): $1^{\circ}-3{ }^{\circ}$ pl. 110-112. Tipo Baccharis L. 110-111. (EQ): $1^{\circ}-^{\circ}$ pl. 112. (P). 113. Tipo Gnaphalium L. (oblíquo). 114-115. Tipo Vernonia Schreb.: $1^{\circ}-2^{\circ}$ pl. $116-117$. Mutisieae 1 (EQ): $1^{\circ}-2^{\circ}$ pl. 118-119. Mutisieae 2 (EQ): $1^{\circ}-2^{\circ}$ pl. $120-122$. Alismataceae: $1^{\circ}-3^{\circ}$ pl. $123-125$. Eriocaulaceae (EQ): $1^{\circ}-3^{\circ}$ pl. 126. Cyperaceae (EQ). 127-129. Poaceae. 127. (EQ). 128-129. $(\mathrm{PD}): 1^{\circ}-2^{\circ} \mathrm{pl}$. ( $\mathrm{pl}=$ planos, $\mathrm{PD}=$ pólo distal, $\mathrm{P}=$ vista polar, $\mathrm{EQ}=$ vista equatorial). 

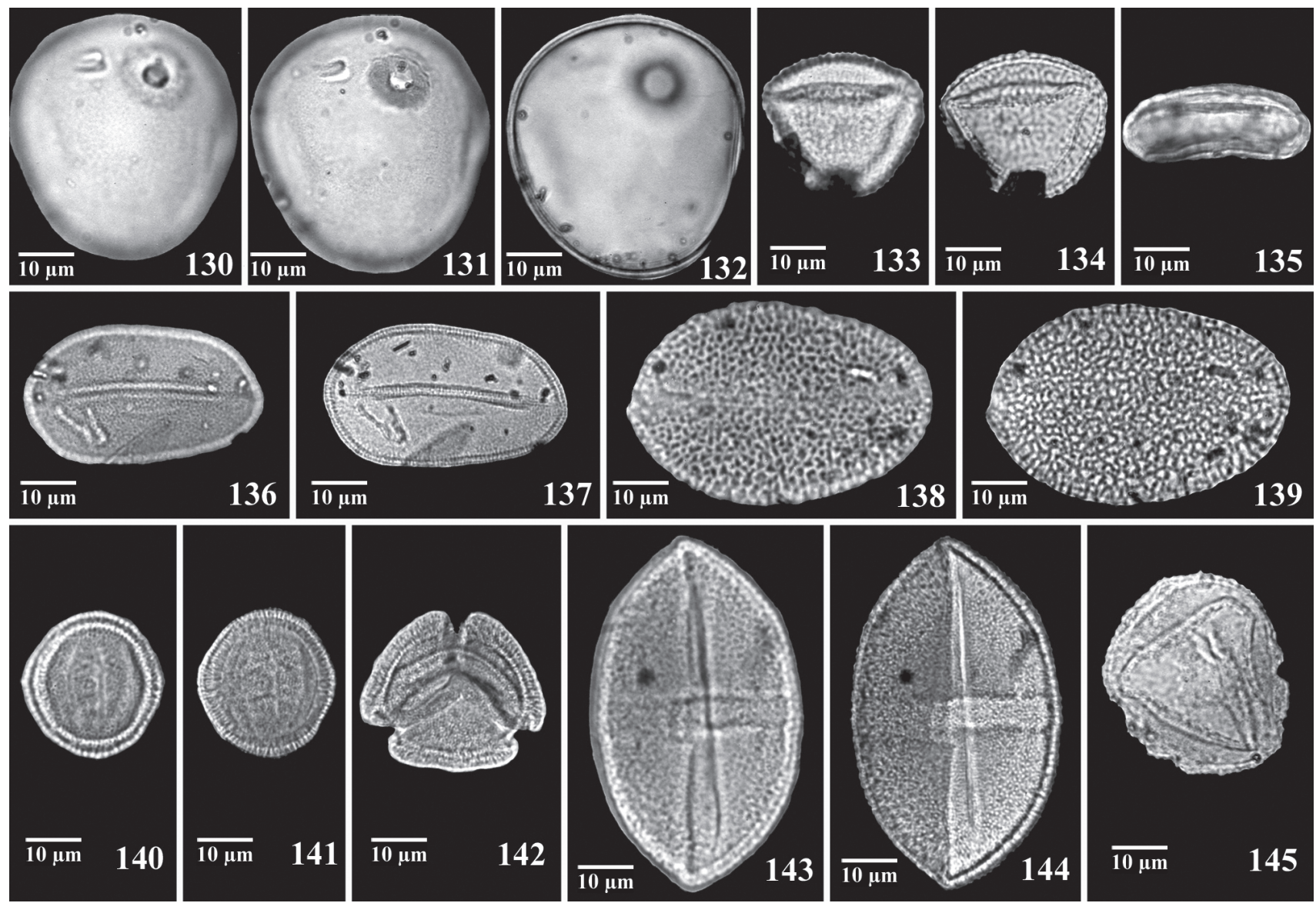

Figuras 130-145. Angiospermas. 130-132. Poaceae (oblíquo): $1^{\circ}-3^{\circ}$ pl. 133-134. Typha L. (PD): $1^{\circ}-2^{\circ}$ pl. 135. Tipo Eichhornia Kunth (EQ). 136-137. Tipo Liliaceae 1 (PD, sulco visto por transparência): $1^{\circ}-2^{\circ} \mathrm{pl}$. 138-139. Tipo Liliaceae 2 (PD): $1^{\circ}-2^{\circ}$ pl. 140-141. Estefanocolpado (EQ): $1^{\circ}-2^{\circ}$ pl. 142 . Tricolporado 1 (P). 143-144. Tricolporado 2 (EQ): $1^{\circ}-2^{\circ}$ pl. 145 . Triporado verrucado $(\mathrm{P}) .(\mathrm{pl}=$ planos, $\mathrm{PD}=$ pólo distal, $\mathrm{P}=$ vista polar, $\mathrm{EQ}=$ vista equatorial $)$.

\section{Agradecimentos}

As autoras agradecem ao Conselho Nacional de Desenvolvimento Cientifico e Tecnológico pelo auxílio financeiro e pelas bolsas concedidas, que tornaram possível a realização deste trabalho.

\section{Referências bibliográficas}

Backes, P. \& Irgang, B.E. 2002. Árvores do Sul. Guia de Identificação e Interesse Ecológico. Porto Alegre, Instituto Souza Cruz.

Baptista, L.R.M. (coord.). 1979. Levantamento florístico preliminar da Reserva Biológica do LAMI - Porto Alegre, RGS. Nideco, Série Urbana 1: 1-30

Behling, H.; Bauermann, S.G. \& Neves, P.C.P. 2001. Holocene environmental changes in São Francisco de Paula region, southern Brazil. Journal of South American Earth Sciences 14: 631-639.

Behling, H.; Pillar, V.D.P.; Orlóci, L. \& Bauermann, S.G. 2004. Late Quaternary Araucaria forest, grassland (campos), fire and climate dynamics, studied by high resolution pollen, charcoal and multivariate analysis of the Cambará do Sul core in southern Brazil. Palaeogeography, Palaeoclimatology, Palaeoecology 203: $277-297$

Berglund, B.E. 1986. Handbook of Holocene Palaeoecology and Palaeohydrology. New York, John Wiley \& Sons.

Bold, H.C.; Alexopoulos, C.J. \& Delevoryas, T. 1987. Morphology of Plants and Fungi. $5^{\text {th }}$ ed. New York, Harper \& Row Publishers.
Boldrini, I.I.; Longhi-Wagner, H.M. \& Boechat, S.C. 2005. Morfologia e taxonomia de gramíneas sul-rio-grandenses. Porto Alegre, Editora da UFRGS.

Burkart, A. 1979. Leguminosas, Mimosóideas. Pp. 1-299. In: R. Reitz (ed.). Flora Ilustrada Catarinense. Itajaí, Herbário Barbosa Rodrigues.

Ceroni, Z.S.V. 1973. Lista dos gêneros de Caryophyllaceae do Rio Grande do Sul - Brasil. Iheringia, Série Botânica 18: 98-103.

Cronquist, A. 1981. An integrated system of classification of flowering plants. New York, Columbia University Press.

Erdtman, G. 1957. Pollen and Spore Morphology / Plant Taxonomy. Gymnospermae, Pteridophyta, Bryophyta. New York, The Ronald Press Company.

Faegri, K. \& Iversen, J. 1989. Textbook of pollen analysis. $4^{\text {th }}$ ed. New York, John Wiley \& Sons.

Fevereiro, P.C.A. 1975. Haloragáceas. Pp. 1-17. In: R. Reitz (ed.). Flora Ilustrada Catarinense. Itajaí, Herbário Barbosa Rodrigues.

Delprete, P.G.; Smith, L.B. \& Klein, R.M. 2004. Rubiáceaes. Volume I - Gêneros de A-G: 1. Alseis até 19. Galium. Pp. 1-345. In: A. Reis (ed.). Flora Ilustrada Catarinense. Itajaí, Herbário Barbosa Rodrigues.

Delprete, P.G.; Smith, L.B. \& Klein, R.M. 2005. Rubiáceaes. Volume II - Gêneros de H-T: 20. Gardenia até 46. Tocoyena. Pp. 346-842. In: A. Reis (ed.). Flora Ilustrada Catarinense. Itajaí, Herbário Barbosa Rodrigues.

Edwin, G. \& Retz, R. 1967. Aquifoliáceas. Pp. 1-47. In: R. Reitz (ed.). Flora Ilustrada Catarinense. Itajaí, Herbário Barbosa Rodrigues. 
Fleig, M. 1987. Anacardiaceae. Boletim do Instituto de Biociências 42: $1-72$.

Girardi, A.M.M. 1975. Meliaceae. Boletim do Instituto de Biociências 33: 1-64.

Harley, R.M. 1985. Labiadas. Pp. 1-72. In: R. Reitz (ed.). Flora Ilustrada Catarinense. Itajaí, Herbário Barbosa Rodrigues.

Ichaso, C.L.F. \& Barroso, G.M. 1970. Escrofulariáceas. Pp. 1-114. In: R. Reitz (ed.). Flora Ilustrada Catarinense. Itajaí, Herbário Barbosa Rodrigues.

Irgang, B.E. 1974. Umbelliferae. Boletim do Instituto de Biociências 32: 1-86.

Irgang, B.E. \& Gastal Junior, C.V.S. 1996. Macrófitas aquáticas da Planície Costeira do RS. Porto Alegre.

Joly, A.B. 2002. Botânica: introdução à taxonomia vegetal. $13^{a}$ ed. São Paulo, Editora Nacional.

Leonhardt, A. \& Lorscheitter, M.L. 2007. Palinomorfos do perfil sedimentar de uma turfeira em São Francisco de Paula, Planalto Leste do Rio Grande do Sul, Sul do Brasil. Revista Brasileira de Botânica 30: 47-59.

Lourteig, A. 1969. Litráceas. Pp. 1-80. In: R. Reitz (ed.). Flora Ilustrada Catarinense. Itajaí, Herbário Barbosa Rodrigues.

Lüdtke, R. \& Miotto, S.T.S. 2004. O gênero Polygala L. (Polygalaceae) no Rio Grande do Sul, Brasil. Revista Brasileira de Biociências 2: $49-102$.

Marchant, R.; Almeida, L.; Behling, H.; Berrio, J.C.; Bush, M.; Cleef, A.; Duivenvoorden, J.; Kappelle, M.; Oliveira, P.; Oliveira Filho, A.T.; Lozano-Garæia, S.; Hooghiemstra, H.; Ledru, M.P.; LudlowWiechers, B.; Markgraf, V.; Mancini, V.; Paez, M.; Prieto, A.; Rangel, O. \& Salgado-Labouriau, M.L. 2002. Distribution and ecology of parent taxa of pollen lodged within the Latin American Pollen Database. Review of Palaeobotany and Palynology 121: $1-75$.

Matzenbacher, N.I. \& Mafioleti, S.I. 1994. Estudo taxonômico do gênero Vernonia Schreb. (Asteraceae) no Rio Grande do Sul, Brasil. Comunicações do Museu de Ciências e Tecnologia PUCRS, Série Botânica 1: 1-133.

Moldenke, H.N. \& Smith, L.B. 1976. Eriocauláceas. Pp 1-103. In: R. Reitz (ed.). Flora Ilustrada Catarinense. Itajaí, Herbário Barbosa Rodrigues.

Porto, M.L. 1974. Cucurbitaceae. Boletim do Instituto de Biociências 31: 1-64.

Porto, M.L. \& Mariath, J.E.A. 1975. Taxonomia numérica de algumas entidades do gênero Relbunium (Endl.) Hook. f. (Rubiaceae). Iheringia, Série Botânica 20: 3-16.

Punt, W.; Hoen, P.P.; Blackmore, S.; Nilsson, S. \& Thomas, A.Le. 2007. Glossary of pollen and spore terminology. Review of Palaeobotany and Palynology 143: 1-81.
Rambo, B. 1956. A flora fanerogâmica dos Aparados riograndenses. Sellowia 7: 235-298.

Rahn, K. 1966. Plantagiáceas. Pp. 1-37. In: R. Reitz (ed.). Flora Ilustrada Catarinense. Itajaí, Herbário Barbosa Rodrigues.

Reitz, R. 1968. Sapotáceas. Pp. 1-72. In: R. Reitz (ed.). Flora Ilustrada Catarinense. Itajaí, Herbário Barbosa Rodrigues.

Reitz, R. 1980. Sapindáceas. Pp. 1-156. In: R. Reitz (ed.). Flora Ilustrada Catarinense. Itajaí, Herbário Barbosa Rodrigues.

Reitz, R. 1984. Tifáceas. Pp. 1-14. In: R. Reitz (ed.). Flora Ilustrada Catarinense. Itajaí, Herbário Barbosa Rodrigues.

Reitz, R., Klein, R.M. \& Reis, A. 1983. Projeto madeira do Rio Grande do Sul. Sellowia 34/35: 1-525.

Roth, L. \& Lorscheitter, M.L. 1993. Palynology of a bog in Parque Nacional de Aparados da Serra, East Plateau of Rio Grande do Sul, Brazil. Quaternary of South America and Antarctic Peninsula 8: 39-69.

Sandwith, N.Y. \& Hunt, D.R. 1974. Bignoniáceas. Pp. 1-172. In: R. Reitz (ed.). Flora Ilustrada Catarinense. Itajaí, Herbário Barbosa Rodrigues.

Scherer, C. \& Lorscheitter, M.L. 2008. Palinomorfos de fungos e criptógamas em sedimentos quaternários de duas matas com Araucária, Planalto leste do Rio Grande do Sul, Brasil. Acta Botanica Brasilica 22: 131-144.

Schultz, A.R. 1990. Introdução à botânica sistemática. v.2. $5^{\text {a }}$ ed. Porto Alegre, Sagra, Ed. UFRGS.

Smith, L.B.; Downs, R.J. \& Klein, R.M. 1988. Euforbiáceas. Pp. 1-408. In: R. Reitz (ed.). Flora Ilustrada Catarinense. Itajaí, Herbário Barbosa Rodrigues.

Sobral, M. 1999. Valerianaceae. Boletim do Instituto de Biociências 58: 1-61.

Sobral, M. 2003. A família Myrtaceae no Rio Grande do Sul. São Leopoldo, Ed. UNISINOS.

Souza, V.C. \& Lorenzi, H. 2005. Botânica sistemática: guia ilustrado para identificação de Angiospermas da flora brasileira, baseado em APG II. Nova Odessa, Instituto Plantarum.

Taylor, P.G. 1980. Lentibulariáceas. Pp. 1-52. In: R. Reitz (ed.). Flora Ilustrada Catarinense. Itajaí, Herbário Barbosa Rodrigues.

Trinta, E.F. \& Santos, E. 1997. Winteráceas. Pp. 1-19. In: R. Reitz (ed.). Flora Ilustrada Catarinense. Itajaí, Herbário Barbosa Rodrigues.

Vasconcellos, J.M.O. 1973. Estudo dos gêneros de Amaranthaceae do Rio Grande do Sul. Iheringia, Série Botânica 18: 90-97.

Waechter, J.L. 1990. Comunidades vegetais das restingas do Rio Grande do Sul. Pp. 228-248. In: $2^{\circ}$ Simpósio de Ecossistemas da Costa Sul e Sudeste Brasileiro. Águas de Lindóia 1990. São Paulo, ACIESP Ed. v.3. 